\title{
An Inertial two-phase model of wax transport in a pipeline during pigging operations *
}

\author{
Andrea Boghi ${ }^{\mathrm{a}, \star}$, Lloyd Brown ${ }^{\mathrm{b}}$, Robert Sawko ${ }^{\mathrm{c}}$, Christopher P. Thompson ${ }^{\mathrm{c}}$ \\ aSchool of Water, Energy and Environment, Cranfield University, Cranfield, \\ Bedfordshire MK43 OAL, UK \\ ${ }^{\circ}$ Science Deployed, LLC, Katy, Texas, United States \\ AMAC Group, Cranfield University, Cranfield, Bedfordshire MK43 OAL, UK
}

\begin{abstract}
Pig in pipelines performs operations for cleaning the pipe interior and internal inspection. In the past few years many 1D models have been developed to simulate the process because of their reduced computational cost; however, they rely on simplifications which are not always valid. In this paper, the results of a three-dimensional (3D) numerical investigation of the interaction between a waxy-oil and a dynamic sealing pig in a pipeline are presented. The results are obtained at a reduced computational cost by using a moving frame of reference, and an "injection" boundary condition for the wax deposited on the wall. The effect of the temperature and the wax particles' size has been investigated. The 3D results show the structure assumed by the debris field in front of the pig. In particular, a lubrication region at the bottom of the pipe, whose dimensions are temperature dependent, is shown. This information cannot be deduced from 1D modeling. The influence of the oil on the mixture viscosity and the internal bed dynamics are discussed. This work provides insights into the interaction between the debris field in front of the pig and pipeline hydraulics.
\end{abstract}

Keywords: pigging, oil, wax, deposition, pipeline, modeling

\footnotetext{
$\square$ Modeling wax transport during pigging operations

${ }^{*}$ A. Boghi

Email address: a.boghi@cranfield.ac.uk (Andrea Boghi )

${ }^{1}$ A. Boghi

${ }^{2}$ L. Brown

${ }^{3}$ R. Sawko

${ }^{4}$ C. P. Thompson
} 


\section{Introduction}

Pipelines are the most common and safest way to transport oil and gas products. During operation, the pipeline walls suffer a deterioration process and can fail if they are not properly maintained. One part of pipelines maintenance procedure is "pigging" them regularly to prevent the increase of the wall roughness and the reduction of the internal diameter. The device known as "pig" is driven through the pipe by the flow of oil, scraping deposits from the pipe wall as it travels and is used to perform "pigging" operations. Pigging has been widely studied in the past few decades.

McDonald \& Baker (1964) derived the first mathematical model on pigging. The model, valid for spherical pigs, was meant to be used for prediction of the liquid hold-up. Barua (1982) improved the model by removing some limiting assumptions and by considering the slug acceleration.

Kohda et al. (1988) proposed the first two-phase transient pigging model based on correlations. Minami \& Shoham (1995) used a mixed EulerianLagrangian approach to couple the transient two-phase flow with the pig motion. Hosseinalipour et al. (2007b) followed a similar approach, testing a transient model and comparing the results against experimental data.

Azevedo et al. (1996) developed an algebraic, 1D, hydrodynamic model to describe the bypass pig dynamics. The model coefficients were determined through two-dimensional (2D) Computational Fluid Dynamics (CFD) simulations of a Newtonian, incompressible fluid flowing in steady state conditions. The $\mathrm{k}-\epsilon$ model was employed for the simulations.

Lima et al. (1998) and Lima et al. (1999) modeled the liquid removal operation in a gas pipeline. The 1D two-phase model has been solved via a semi-implicit finite difference scheme and the results have been successfully compared with experimental data. Nguyen et al. (2001b) solved the gas mass and momentum equations by using the method of characteristics (MOC) and the Runge-Kutta method. Nguyen et al. (2001c) and Nguyen et al. (2001d) applied the model to a bypass pig case, Nguyen et al. (2001a) to a curved pipe case, and Kim et al. (2003) experimentally verified the model.

Nieckele et al. (2001) developed a single phase fluid model, taking into account wall deformations, and coupled it with the pig momentum equation. A similar approach has been followed by Hosseinalipour et al. (2007a) to simulate the pig motion in gas pipelines. 
Xu \& Gong (2005) developed a simplified pigging model to predict the pigging operation in gas-condensate horizontal pipelines with low liquid-loading. 3 The model has been successfully compared with the OLGA code results. Tolmasquim \& Nieckele (2008) developed a numerical code to simulate the transient oil flow in a pipeline during pigging operations and the results have been compared with field data.

In some works, the pig dynamics in dry conditions (no fluid flow) has been investigated. Hu \& Appleton (2005) developed a dynamic model for a novel pig, designed to move both upstream and downstream, and verified 45 the results against experimental data. Saeidbakhsh et al. (2009) analyzed ${ }_{45}$ the dynamics of small pigs in complex-shaped pipelines. The effect of the

47 flow field was modeled by a time dependent force acting on the pig. The 48 influence of the flow field was successively introduced. The fluid was considered incompressible by Lesani et al. (2012) and compressible by Mirshamsi \& Rafeeyan (2015). In these three works, the dynamics of the system has been solved via a single ordinary differential equation.

Esmaeilzadeh et al. (2009) used the MOC to model the transient motion of a pig through liquid and gas pipelines. The simulation results showed good agreement with the gas-liquid pipeline field data. Deng et al. (2014) used 55 the MOC to study the problem of column separation in gas-liquid pipelines 55 during pigging operations. The simulation results were in good agreement 7 with the field data.

58 Despite many models have been developed to describe the pig dynamics, 59 most of them deal with gas flows and some of them with liquid removal in gas o pipelines. In addition, all the cited models are limited to 1D domain. Waxy 51 oils (wax-particles in oil mixture) in pipelines have been largely studied. 52 Most of the literature focuses on two aspects: wax deposition in oil pipelines 3 (Aiyejina et al. (2011)), and wax removal from pipelines wall (Lima et al. (1995)). Wang et al. (2005) studied the mechanics of wax removal in pipelines 55 in dry conditions, while Wang et al. (2008) repeated the experiments with 55 the oil flowing in the test facility. The tribological behavior of waxy oil 57 subject to pipeline pigging has been investigated in the past few years using 58 the fluorescence technique by Tan et al. $(2014,2015 a)$ and with the portable 9 microscopy technique by Tan et al. (2015b).

70 A few mathematical models tackle the the wax removal from pipeline 71 walls. An example is the one developed by Azevedo et al. (1999) and experi72 mentally verified by Barros Jr et al. (2005). Other pigging models, based on 3 experimental results, have been developed to predict wax deposition (Wang 
74 \& Huang (2014)) and removal in pipelines (Huang et al. (2016)). Wang et al. ${ }_{5}$ (2015) studied experimentally the influence of several parameters on the wax 7 breaking process in order to determine the optimal de-waxing frequency and 7 evaluating the pigging risks. A good review illustrating the forces acting on a bypass pig in operation was written by Galta (2014) .

A few models studying the forces involved in the wax-removal process have been developed based on a mixed experimental-numerical procedure. In particular, Braga et al. (1999) considered the wax deposit as a linear elastic material and neglected the fluid flow, while Southgate (2004) included the oil flow, but considered the wax deposit as rigid and part of the pipe wall. The multiphase wax-oil flow in pipelines during pigging operations has been scarcely studied. An example is the 1D model developed by Hovden et al. (2003) with the OLGA 2000 code, where three different wax deposition models have been tested.

In this paper, a series of three-dimensional (3D) CFD simulations describing the interaction of the waxy oil with the moving pig are presented. Simulating the 3D flow is computationally demanding but has a two-fold advantage compared to the $1 \mathrm{D}$ approach: (i) it increases our understanding of the phenomenon, as it allows the visualization of the interaction between the ${ }_{3}$ pig surface and the wax chips; (ii) the results are less affected by modeling approximations.

\section{Mathematical Modeling}

In this section, the mathematical model describing the dynamics of the oil-wax system in a pipeline, subject to pigging operations, will be illustrated.

\section{2.1. Pig Model}

The main problem in representing the $3 \mathrm{D}$ pig motion numerically is due to the computational grid which must be warped in order to represent the pig displacement. Even though this can be realized with modern computational techniques, it is a computationally demanding operation.

A more convenient approach is to solve the problem in a frame of reference fixed to the pig center of mass, instead to an external observer, as done by Minami \& Shoham (1995); Hosseinalipour et al. (2007b); Nieckele et al. 106 (2001); Tolmasquim \& Nieckele (2008) for 1D modeling. This is possible when the pipeline is straight, with a constant section, and the process is not investigated close to the pumping station or the outlet. Under these 
109 conditions, the computational domain does not change as the time goes by. ${ }_{110}$ As the pig advances, the wax is scraped to accumulate in front of the pig. ${ }_{111}$ Despite the debris field grows in time, it only occupies a small portion of the 112 pipeline.

113 The relationship between the velocity in the absolute frame of reference, ${ }_{114} \square v_{a}$, and the one in the relative frame of reference, $\square v$, is

$$
v \square=\square v_{a}-\square \text { pig }
$$

115 where $\square$ vig is the pig velocity. In order to determine this parameter, two 116 hypothesis were introduced: the pig under investigation is of sealing type, ${ }_{117}$ i.e. no flow between the two sides of the pig, and the oil flow rate,

$$
Q_{o i l}=\int_{A \pi \imath \pi \varepsilon} \square \text { a,oil } \cdot \hat{n} n d A
$$

118 is constant. The mean oil velocity upstream the pig, $U$, is defined as

$$
U=\frac{4 Q_{\text {oil }}}{\square D^{2} \text { pipe }}
$$

119 In order for the mass to be conserved at the interface between the up120 stream oil and the pig, it must be

$$
v_{\text {pig }}=U
$$

$121 \quad$ Eq.(4) can be written because the sealing pig has only one degree of 122 freedom (1DOF), therefore: $v_{\text {pig }}={ }^{\square} v_{\text {pig }} \cdot{ }^{\wedge} n$. In general, the pig could also 123 spin around its axis. Nevertheless, the friction against the wall has been 124 assumed high enough to prevent this. Since the oil flow rate is supposed to 125 be constant, the pig velocity should be constant as well, by virtue of Eq.(4), 126 therefore the pig inertial force, will not influence the dynamics of the oil-wax ${ }_{127}$ system. This is a reasonable approximation as the pig is most effective when 128 it advances at a nearly constant, but not too high, speed as reported by ${ }_{129}$ Nguyen et al. (2001a); Esmaeilzadeh et al. (2009); Deng et al. (2014).

${ }_{130}$ The pig operation is performed when the wax layer reaches a certain 131 thickness hip. Normally, for security purposes, hip is very small compared 132 to the pipe diameter. In order to represent this, the computational grid 133 thickness should be of the same order of the deposit thickness, resulting in a 134 large computational cost. 
Supposing that the wax is uniformly distributed in the circular pipe, and ${ }_{136}$ it is pushed along the pig axis at the pig velocity, the flow rate of scraped wax 137 during the pigging operation is given by:

$$
Q_{\text {wax }}=v_{4}^{v_{p i g}}\left(D_{2 \text { pipe }}-\left(D_{\text {pipe }}-2 h_{w}\right)^{2}\right)
$$

therefore,

$$
\left.v_{\text {inj }}=v_{\text {pig }} \frac{\overline{h_{w}}}{h_{\text {inj }}} 1^{(-} \bar{h}_{D_{\text {pipe }}}\right)
$$

151 In the moving frame of reference, the axial velocity is zero for the pig and 152 the injection area, while in the rest of the pipe wall it is equal to $-v_{\text {pig }} x$, ${ }_{153}$ where $x^{\wedge}$ is the unit vector in the direction of the pipe axis.

\section{2.2. Physical Properties of the System}

155 The debris field in front of the pig is composed of cut wall wax (gel) and 156 oil. The debris field can be considered as a slurry of cut wall wax and oil with 157 variable cut wax content dependent on the wall wax-pig-pipe flow dynamics. 158 The physical properties of oil and wax-in-oil slurry are temperature de159 pendent. They have been derived experimentally, and are illustrated in 160 Fig.(1), where the dependence of the slurry dynamic viscosity on temper${ }_{161}$ ature Fig.(1,a) and wax volume fraction Fig.(1,b), are shown. In Fig.(2), the 162 density Fig.(2,a) and the viscosity Fig.(2,b) of the oil are shown. As Fig.(1) 163 suggests, the pour point of the deposit-contaminated oil is below $-25 F$. 


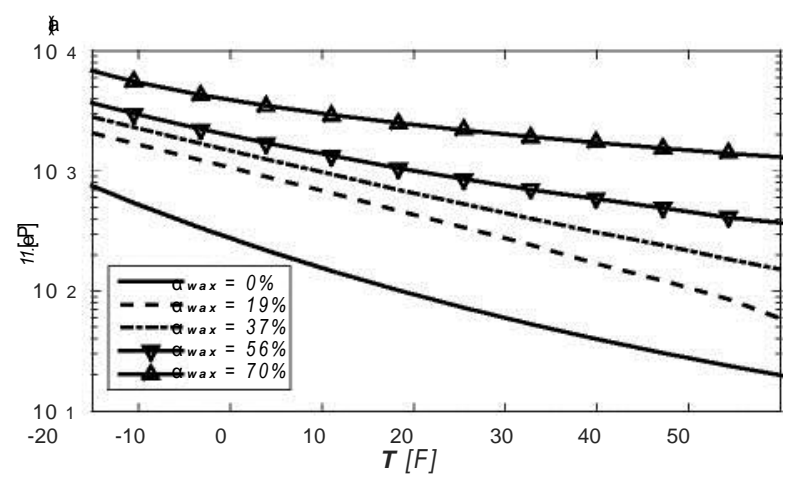

b

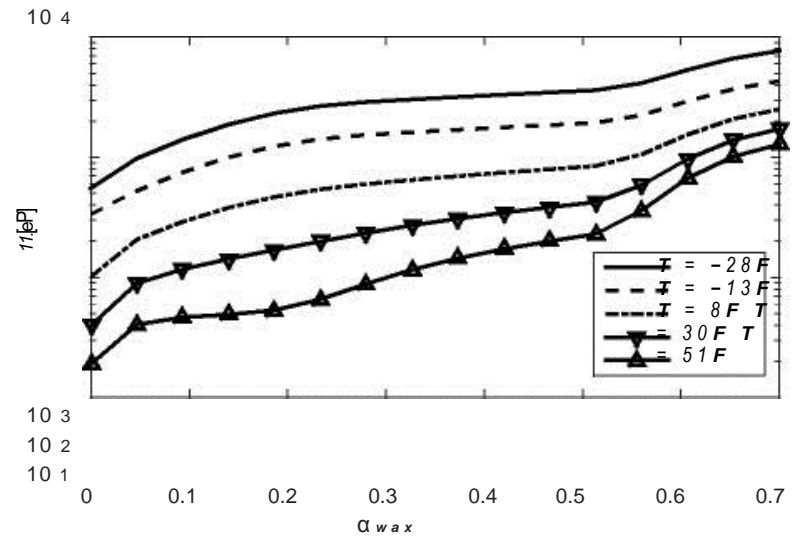

Figure 1: Dynamic viscosity of the wax-in-oil slurry: (a) vs Temperature; (b) vs Volume Fraction.

\section{2.3. Fluid dynamic model}

The flow of the mixture has been simulated with the drift flux model, 166 which is widely used in multiphase modeling (Aarsnes et al. (2016); Varadarajan \& Hammond (2015); Bhagwat \& Ghajar (2014); Chen et al. (2012); Asheim \& Grødal (1998); Gavrilyuk \& Fabre (1996); Fran ca \& Lahey (1992); Clark et al. (1990)), and solves the conservation of mass, momentum and energy of the mixture only. This implies that the momentum of each phase is not calculated explicitly and the inter-phase phenomena, such as settling, require modeling. In addition, a transport equation for the volume fraction ${ }_{3}$ of each phase is provided. In this work, the wax-in-oil slurry flow is consid${ }_{4}$ ered to be laminar. This can be achieved if the pipe diameter is sufficiently ${ }_{5} 5$ small, because of the high wax viscosity. Moreover, the flow has been consid${ }_{276}$ ered isothermal and therefore the energy equation has not been considered. 

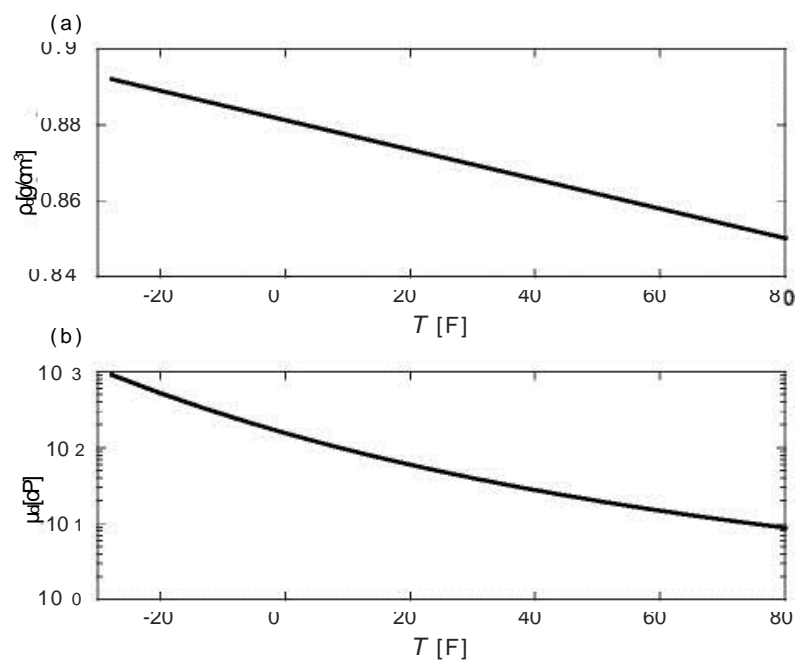

Figure 2: Oil properties: (a) density; (b) dynamic viscosity

177 The reduced pipe diameter and length limit the surface of heat exchange, 178 justifying that this assumption is valid if the observation time is small and 179 is suitable for non-heated pipelines.

180 The wax volume fraction in the slurry, awax, is defined as:

$$
\square \text { wax }=V_{\text {wax }}
$$

$V_{\text {rev }}$
where ${ }_{\text {Vrev }}$ is the Representative Volume Element (REV) which is the

182 smallest volume over which a measurement can be made that will yield a

183 value representative of the whole. Since in the domain of investigation there

184 are only oil and wax particles, the following relationship applies:

$$
\square \text { oil }=1-\square \text { wax }
$$

185 The continuity equation for the wax phase can be written as:

$$
\begin{gathered}
a t_{186 \quad\left(P_{\text {wax }} a_{\text {wax }}\right)+\operatorname{div}\left(P_{\text {waxawax }}\left(\square \mathrm{v}_{m}+\square \mathrm{v} d_{w}\right)\right)=0} \text { where } \\
\qquad v_{d w}={ }^{\square} v_{\text {wax }}-\square v_{m}
\end{gathered}
$$


is the drift velocity,

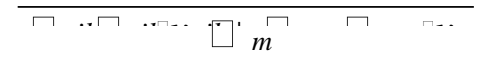

the mixture velocity, and,

$$
\square_{m}=\square \text { oil } \square \text { oil }+\square \text { wax } \square \text { wax }
$$

the mixture density. Adding up the mass conservation of each phase, e.g. ${ }_{190}$ Eqs. $(9,10)$, the conservation of mass for the mixture can be obtained as:

$$
\square \square m+\operatorname{div}\left(\square \mathrm{m} \square \mathrm{v}_{\mathrm{m}}\right)=0
$$

The mixture momentum equation can be written as

$$
\square t\left(\square m \square v_{m}\right)+\operatorname{div}\left(\square \mathrm{m} \square \mathrm{v}_{\mathrm{m}} \square \square \mathrm{v}_{\mathrm{m}}\right)=-\nabla \mathrm{p}_{\mathrm{m}}+\operatorname{div}\left([\square \mathrm{m}]+\left[\square \mathrm{d}_{\mathrm{m}}\right]\right)+
$$

192 where $p_{m}$ is the mixture pressure, or just pressure,

$$
[\square d m]=\quad \square \text { oil } \square \quad \square^{\square} v d w \square{ }^{\square} v d w
$$

$193 \quad$ is the drift stress tensor, and

$$
[\square m]=\mu_{m}\left(T, \underset{a w a x}{ }\left[\begin{array}{c}
( \\
{\left[\square v_{m}\right]+\left[\nabla \square v_{m}\right]^{T}-2 \operatorname{div}\left(\square \mathrm{v}_{\mathrm{m}}\right)[\mathrm{I}]}
\end{array}\right.\right.
$$

194 the viscous stress tensor with $[I]$ the identity tensor and $\mu_{m}(T, \square$ wax $)$ 195 the mixture viscosity which, as can be seen from the experimental data in ${ }_{196}$ Fig.(1), is a function of both the temperature and the wax volume fraction. ${ }_{197}$ Further details on the Drift Flux Model can be found in Rusche (2003). ${ }_{198}$ As it can be seen from Eqs.(10,16,17), the model is complete once the ${ }_{199}$ expression of the drift velocity and mixture viscosity are supplied.

\section{2.4. Mixture Viscosity Model}

201 The mixture viscosity has been derived experimentally and the results 202 are shown in Fig.(1). The slurry viscosity was measured in a rotational vane 203 rheometer at constant constant shear rate of $301 / \mathrm{s}$ as the temperature was 204 reduced uniformly from the wax appearance temperature $(80 F)$ to $-28 F$ 
Table 1: Coefficients of the Mixture Viscosity Model

\begin{tabular}{rclccc}
\hline$T(F)$ & $b_{1}$ & \multicolumn{1}{c}{$b_{2}$} & $b 3$ & $b 4$ & $r^{2}$ \\
\hline-25 & 7.9805 & -3.342 & 2.1055 & 0.48004 & 0.9770 \\
\hline 0 & 18.516 & -7.3499 & 3.1263 & 0.38464 & 0.9905 \\
\hline 25 & 18.583 & -6.515 & 3.3366 & 0.53254 & 0.9790 \\
\hline 50 & 8.9526 & -1.7972 & 3.4096 & 0.63734 & 0.9490 \\
\hline \hline
\end{tabular}

205 Over 18 hours. The measurement have been performed at varying volumetric 206 fractions of cut wax. At each temperature, the mixture viscosity shows a 207 discontinuous slope for $\square$ wax $=0.5$, appearing to reach an asymptote near $208 \square$ wax $=0.7$, which is the maximum packing fraction. This is consistent with 209 the change of particle arrangement. For $\square$ wax $<0.5$ the wax chips are more 210 free to move and their orientation is random; above this value the chips start 211 packing and the mixture viscosity increases abruptly. In order to fit the 212 experimental data, the following relationship is introduced:

$$
\ln \frac{\left(\mu_{m}(T, \square \text { wax })\right)}{\mu_{m}(T, 0)} \quad=\max \frac{(\underline{b 1(T) \square \text { wax }} \quad, \quad \underline{b 3(T) \square \text { wax }}}{1-b 2(T) \square \text { wax }^{1}-b 4(T) \square \text { wax }}
$$

$213 \quad$ In Tab.(1) the $b_{i}$ coefficients, along with the square correlation coefficient ${ }_{214} r^{2}$, which shows how well the model in Eq.(18) reproduces the experimental 215 results, are reported. It must be noted that the value $\mu_{m}(T, 0)$ is not in that 216 table, because it corresponds to the oil viscosity and will be shown in Tab.(3)

217 2.5. Drift Velocity Model

$$
\begin{aligned}
& { }^{218} \quad \text { The Stokes' velocity, which is the terminal velocity } \\
& \square v_{s}=\begin{array}{l}
{ }^{219} \text { laminar regime, reads: } \\
18
\end{array}
\end{aligned}
$$

$\mu$ oil

$220 \quad$ In case of hindered settling, an alternative expression has been proposed 221 by Camenen (2008)

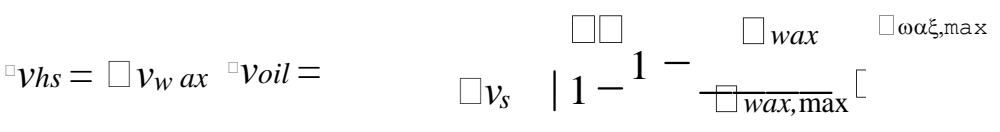


Table 2: Settling velocity

\begin{tabular}{rccccr}
\hline$T(F)_{d w a x}(\mathrm{~mm})$ & $v_{s}(\mathrm{~mm} / \mathrm{s})$ & \multicolumn{2}{c}{$\mathrm{Re}_{\mathrm{p}}$} & $n$ \\
\hline-25 & 2 & -0.251 & $5.8 \cdot 10^{-4}$ & 4.6 \\
\hline 0 & 2 & -1.369 & $1.5 \cdot 10^{-2}$ & 4.6 \\
\hline 25 & 2 & -4.857 & $1.7 \cdot 10^{-1}$ & 4.6 \\
\hline 50 & 2 & -12.97 & \multicolumn{2}{c}{1.1} & 4.35 \\
\hline-25 & 0.4 & -0.010 & $4.6 \cdot 10^{-6}$ & 4.6 \\
\hline 0 & 0.4 & -0.055 & $1.2 \cdot 10^{-4}$ & 4.6 \\
\hline 25 & 0.4 & -0.194 & $1.4 \cdot 10^{-3}$ & 4.6 \\
\hline 50 & 0.4 & -0.519 & $8.9 \cdot 10^{-3}$ & 4.6 \\
\hline \hline
\end{tabular}

where $\square$ wax,max is the maximum volume fraction, which in this work has 223 been assumed equal to 0.7 , and $n$ is an exponent defined as

$$
\begin{aligned}
& n=\square \quad 4.4 \operatorname{Re}_{-0.03}^{4.6} \text { for } \operatorname{Re}_{\mathrm{p}}<0.2 \\
& \begin{array}{ll}
4.4 R e-0.03 & \text { for } 0.2<\operatorname{Re}_{\mathrm{p}}<1 \\
\mathrm{p} & \text { for } 1<\operatorname{Re}_{\mathrm{p}}<500
\end{array} \\
& 2.4 \text { for } \mathrm{Re}_{\mathrm{p}}>500
\end{aligned}
$$

224 where $\mathrm{Re}_{\mathrm{p}}$ is the particle Reynolds number defined as

$$
\operatorname{Re}_{\mathrm{p}}=\square \text { oil }|\square v \mathrm{vs}| \mathrm{d}_{\mathrm{wax}}
$$

The settling velocity in Eq.(20) has been validated against experimen226 tal data on particles of different shapes and dimensions (Camenen (2008)).

227 Therefore, in this context the particle diameter is the largest distance be228 tween two points of the particle.

229 Finally, the drift velocity reads:

$$
\nabla_{d w}=\frac{\square \text { oil } \square o}{\square m}{ }{ }_{\text {vhs }}
$$

In Tab.(2) the settling velocity values for different temperatures and par231 ticle diameters have been reported along with the particle Reynolds number 232 and the exponent $n$ appearing in Eqs. $(20,22)$. 


\section{2з3 3. Materials and Method}

The simulations have been performed using the driftFluxFoam solver, available in OpenFOAM v3.0, which solves the fluid dynamics equations with the Finite Volume Method (FVM) and uses the SIMPLE algorithm for the pressure-velocity coupling. The computational grid has been realized with the blockMesh utility of OpenFOAM v3.0. Only the pipe in front of the pig, which has a diameter of $3 \mathrm{in}$ and is 60 diameters long, has been considered as the domain of investigation, since a constant oil flow rate of $37 \mathrm{USgal} / \mathrm{min}$ has been imposed. These dimensions are not typical of oil pipelines but can be found in test facilities (Barros Jr et al. (2005); Team (2011); Wang et al. (2015); Huang et al. (2016)). The front pig wall is steady, because of the moving frame of reference, while the pipe wall is moving backwards at the pig speed. In order to ensure mass conservation, both pig and mean oil velocity are equal to $1.7 \mathrm{ft} / \mathrm{s}(0.51 \mathrm{~m} / \mathrm{s})$.

At the injection area only wax is present, with an injection velocity given by Eq.(7) and directed radially inwards. This condition represents the scraping of a $2 \mathrm{~mm}$ thick wax deposit. The resulting flow rate of scraped wax is about 3.78USgal/min, regardless of the particle diameter. Therefore, the smaller the particles, the higher their number. Since the injection boundary condition, defined in Eq.(7), decouples the flow rate of scraped wax from the particle diameter, it is possible to study the influence of these two parameters separately.

The velocity normal derivative is set to zero at the outlet boundary (Neumann boundary condition). As far as the volume fractions are concerned, the normal derivative is set to zero everywhere except at the injection area, where a fixed volume fraction is imposed. This corresponds to zero mass flux at the boundary (Vorobev \& Boghi (2016)).

Eight simulations have been set up. Four different temperatures, i.e. $-25 F, 0 F, 25 F, 50 F$, and 2 particle diameters, i.e. $2 \mathrm{~mm}, 0.4 \mathrm{~mm}$, have been investigated. The uniform particle diameter is an approximation made to study the effect of this parameter. In reality, during the scraping process, particles of different dimensions are injected into the pipe. The temperatures chosen are very low, and the particle diameters high. Nevertheless, these extreme conditions can be found in the trans Alaska pipeline system (Team (2011)) and have been chosen to provoke crystallization in a short length, and obtain a developed wax-in-oil slurry in a short model time. 


\section{4. Results}

270 The simulations have been performed on the Astral Cluster with Xeon 2715160 dual core processors at Cranfield University. Each simulation run on 32 272 processors and took approximately 4 hours and 40 minutes, on a grid made 273 of 518400 hexaedra, to be completed.

274 The results are grouped in two categories: Results at $2 \mathrm{~mm}$ wax particle 275 diameter, and Results at $0.4 \mathrm{~mm}$ wax particle diameter. The results will be 276 expressed in terms of section averaged variables as well, since many pipeline 277 codes provide them.

278 The wax area fraction is defined as:

$$
\begin{gathered}
\square 79 \quad \square \text { wax }(t, x)=\frac{\int_{1} 2 / r \int_{R}}{\square R_{200}} \square \text { wax }(t, r, \square, x) r d r d \square \\
\square m(t, x)=\square \text { oil }+(\square \text { wax }-\square \text { oil }) \square \text { wax }(t, x)
\end{gathered}
$$

280 the section averaged momentum is defined as:

$$
\square_{m}(t, x) U_{m}(t, x)=
$$

281 the section averaged pressure drop is defined as:

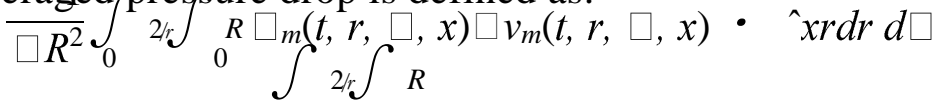

$$
\begin{aligned}
& \left.p(t, x)=p_{\square}^{\frac{1}{(} t}, r, \square, x\right) r d r d \square
\end{aligned}
$$

282 For a single phase flow, the pressure drop can be calculated according to 283 the following formula:

$$
p_{\text {oil }}(t, x)-p_{\text {out }}=\square \text { oil } 2\left(4 Q _ { B ^ { i } } { } ^ { \prime 2 } \quad \left(1+\square\left(\operatorname{Re}_{o i l}, \epsilon / \mathrm{D}\right) L_{D}{ }^{\prime}{ }^{\prime}\right.\right.
$$

$284 \quad$ Where Qoil is the mean oil velocity, $D$ the hydraulic diameter and $\square$ ' is the 285 local friction factor which takes into account the localized loss of charge due 286 to the fact that the velocity profile at the pig surface is not fully developed ${ }_{287}$ (Al-Nassri \& Unny (1981)). This coefficient has been derived by performing a 
Table 3: Properties used for the simulations

\begin{tabular}{rcccrrc}
\hline$T(F)$ & $p_{\text {oil }}\left(\mathrm{g} / \mathrm{cm}^{3}\right)$ & $p_{\text {wax }}\left(\mathrm{g} / \mathrm{cm}^{3}\right)$ & $\mu$ oil $(\mathrm{cP})$ & $\mu_{\text {wax }}(\mathrm{cP})$ & $\mathrm{Re}_{\text {oil }}$ & $\Delta p_{\text {ref }}(\mathrm{kPa})$ \\
\hline-25 & 0.891 & 0.98 & 771.71 & 7103.6 & 45 & 9.96 \\
\hline 0 & 0.881 & 0.98 & 157.68 & 3150.5 & 218 & 2.03 \\
\hline 25 & 0.871 & 0.98 & 48.92 & 2026.2 & 695 & 0.63 \\
\hline 50 & 0.861 & 0.98 & 20.00 & 1487.7 & 1680 & 0.26 \\
\hline \hline
\end{tabular}

s series of numerical simulations at different temperatures with only oil flowing in the pipeline, and its value has been found equal to 0.1 approximately for every temperature.

291 In Tab.(3) the properties used for the simulations have been reported. 92 The density and viscosity values have been experimentally determined and 293 have been shown in Fig.(1) and Fig.(2). It must be noted that $\mu$ oil $=$ $294 \mu_{m}\left(T, a_{w a x}=0\right)$ and $\mu_{w a x}=\mu_{m}\left(T, a_{w a x}=0.7\right)$. The last two values in 295 Tab.(3) refer to the simulations in which only pure oil is flowing. As $\mu$ oil is 296 the minimum value for the mixture viscosity and Reoil is the highest Reynolds 297 number for the wax-in-oil slurry flow, the mixture flows in laminar regime. 298 Moreover, $\Delta p r e f$ is the pressure drop in the domain when only pure oil is 299 flowing, and it is the lowest pressure drop which can occur in the domain.

300 4.1. Results at $2 \mathrm{~mm}$ wax particle diameter

301 The cut wax volume fraction field is shown in Fig.(3). The solutions at 302 different temperatures are compared. The volume fraction field appears to 303 be more diffuse at lower temperatures. This is due to the fact that the oil 304 viscosity increases with the decreasing temperature. This reduces the settling 305 velocity $v_{s}$ and increases the wax particles dispersion.

306 When the pig scrapes the wax deposit at $T=-25 F$, the wax particles 307 travel a relatively long distance, because of the small settling velocity. There308 fore, at the bottom of the pipe a region can be observed, 40 diameters long 309 and half a diameter high, in which the wax volume fraction is relatively low $310(\square 35 \%)$. This will be called "lubrication region", because it is characterized 311 by a low viscosity, as Fig.(1) suggests. 
312 At $T=0 F$ a lubrication region at the pipe bottom, 28 diameters long, 313 can be observed as well. This region is shorter than the previous case but 314 its wax content is higher ( $\square 50 \%$ ). A high wax content region can be seen 315 downstream the lubrication region. Nevertheless, due to the low settling, 316 its boundaries cannot be clearly defined. In this region, also present for ${ }_{317} T=-25 F$, the particles settle. Further downstream another low wax content 318 region can be seen.

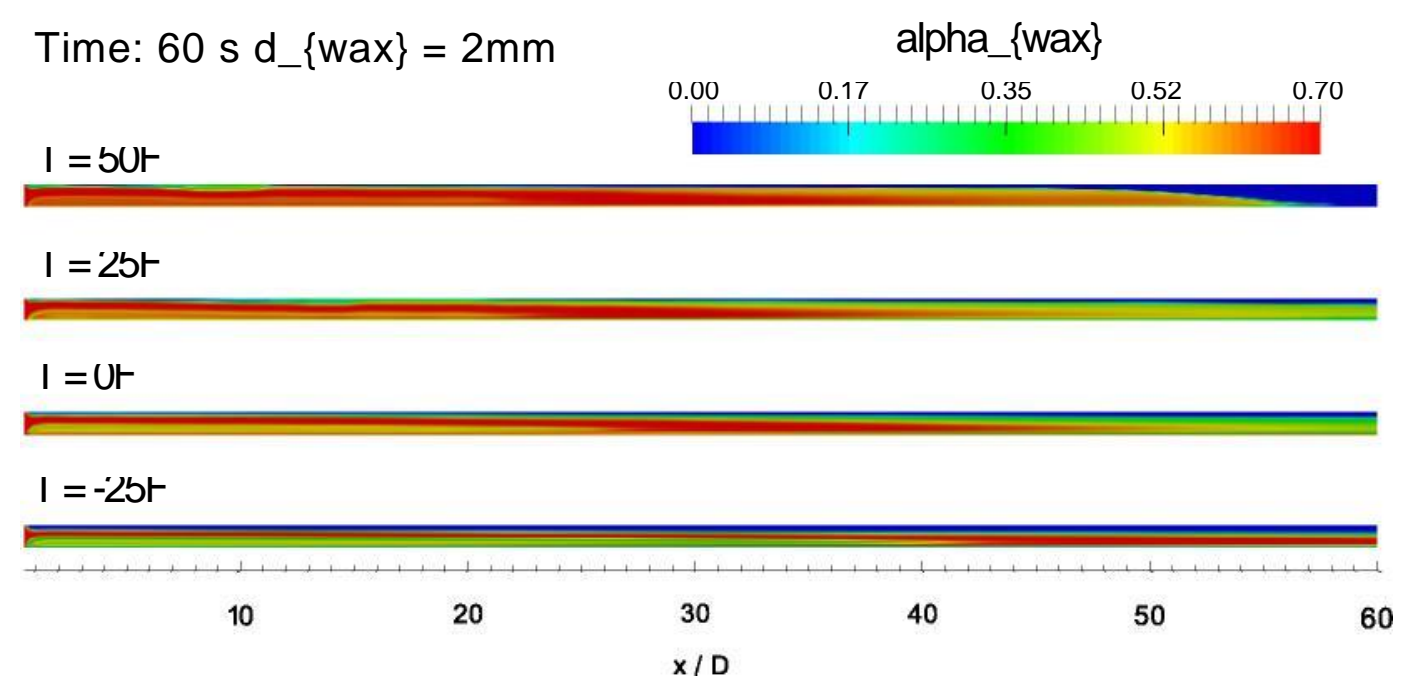

Figure 3: Wax volume fraction field for $2 \mathrm{~mm}$ particle diameter at 60 seconds after the beginning of the process.

319 The wax debris field is similar to the previous cases for $T=25 \mathrm{~F}$ and $320 T=50 F$ with a shorter and more viscous lubrication region. A remarkable 321 difference can be observed for $T=50 F$, where only pure oil can be seen 322 downstream the high wax content region. This is due to the high settling 323 velocity which promotes wax deposition.

324 In Fig.(4) the section averaged wax debris field, defined in Eq.(24), at 325 different instants of time is shown. The stratified debris field assumes a ${ }_{326}$ "dune" shape. The wax distribution increases slightly in height compared 327 to the length. This means that the height of the dune, is mostly set at the 328 beginning of the operations. Therefore, the fluid dynamic conditions at the 329 pig front surface must play an important role in determining this parameter.

It is interesting to compare the 3D information given in Fig.(3), with the 

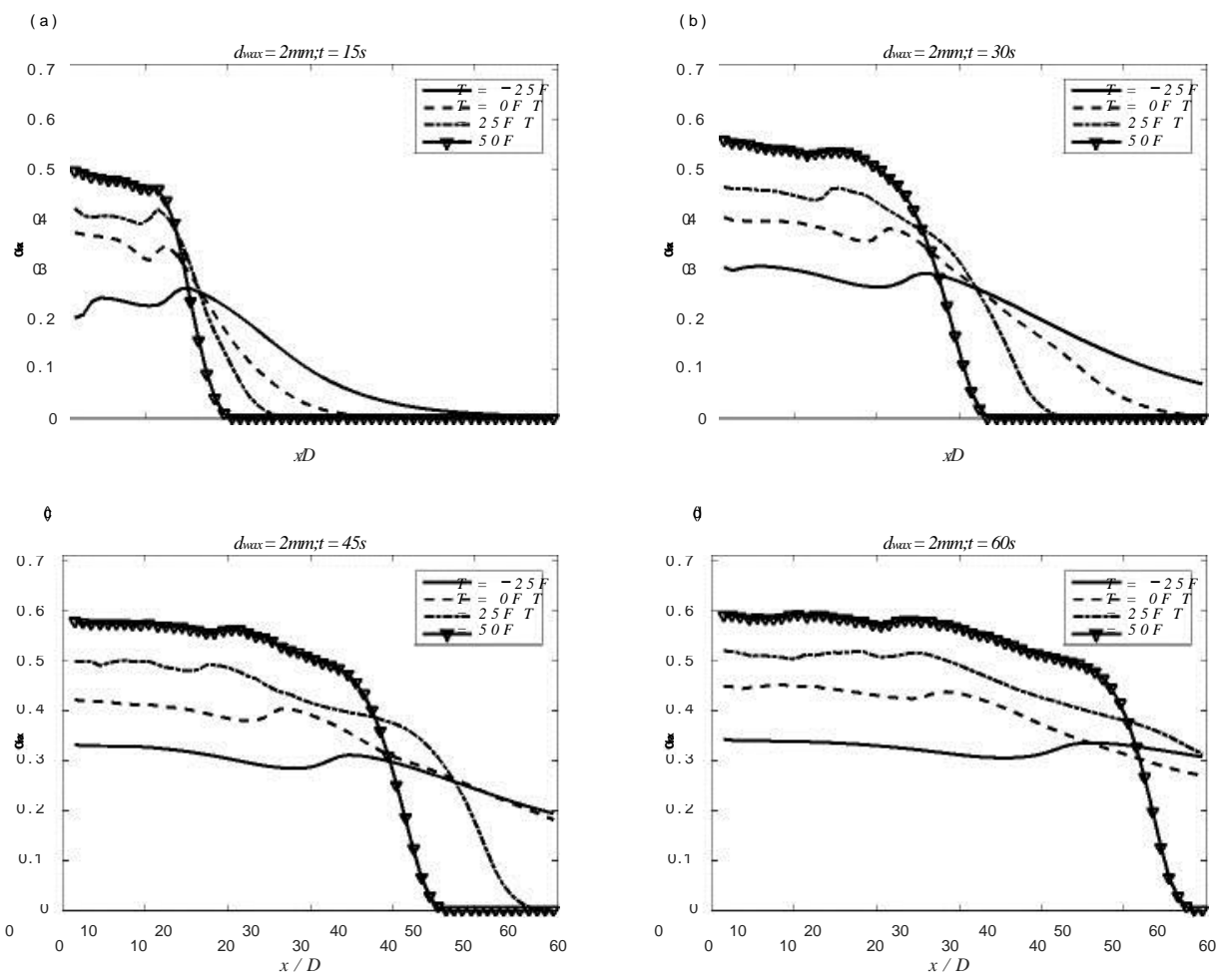

Figure 4: Section averaged cut wax volume fraction field for $2 \mathrm{~mm}$ particle diameter. (a) $\mathrm{t}=15 \mathrm{~s}$; (b) $\mathrm{t}=30 \mathrm{~s}$; (c) $\mathrm{t}=45 \mathrm{~s}$; (d) $\mathrm{t}=60 \mathrm{~s}$.

${ }_{331} 1 \mathrm{D}$ in Fig. $(4, \mathrm{~d})$. The section average is more representative of the instan332 taneous field at higher temperatures because the debris distribution is more $3 з 3$ uniform. The presence of a lubrication region cannot be deduced from the ${ }_{34} 1 \mathrm{D}$ field.

For awax at $T=-25 F$ the wax-in-oil slurry is stratified: the top layer 36 contains $0 \%$ of wax (oil layer), the second layer contains about $70 \%$ of wax, and the bottom layer contains $35 \%$ of wax. However, it is not possible to retrieve this information from the section averaged field.

This is very important as the pressure drop across the pipe is influenced by the local viscosity that depends on the wax distribution. A simplified 1D model which does not take into account the wax distribution, risks to give an unreliable estimation of the pressure drop.

343 The time growth of the wax-in oil slurry is an interesting output for 

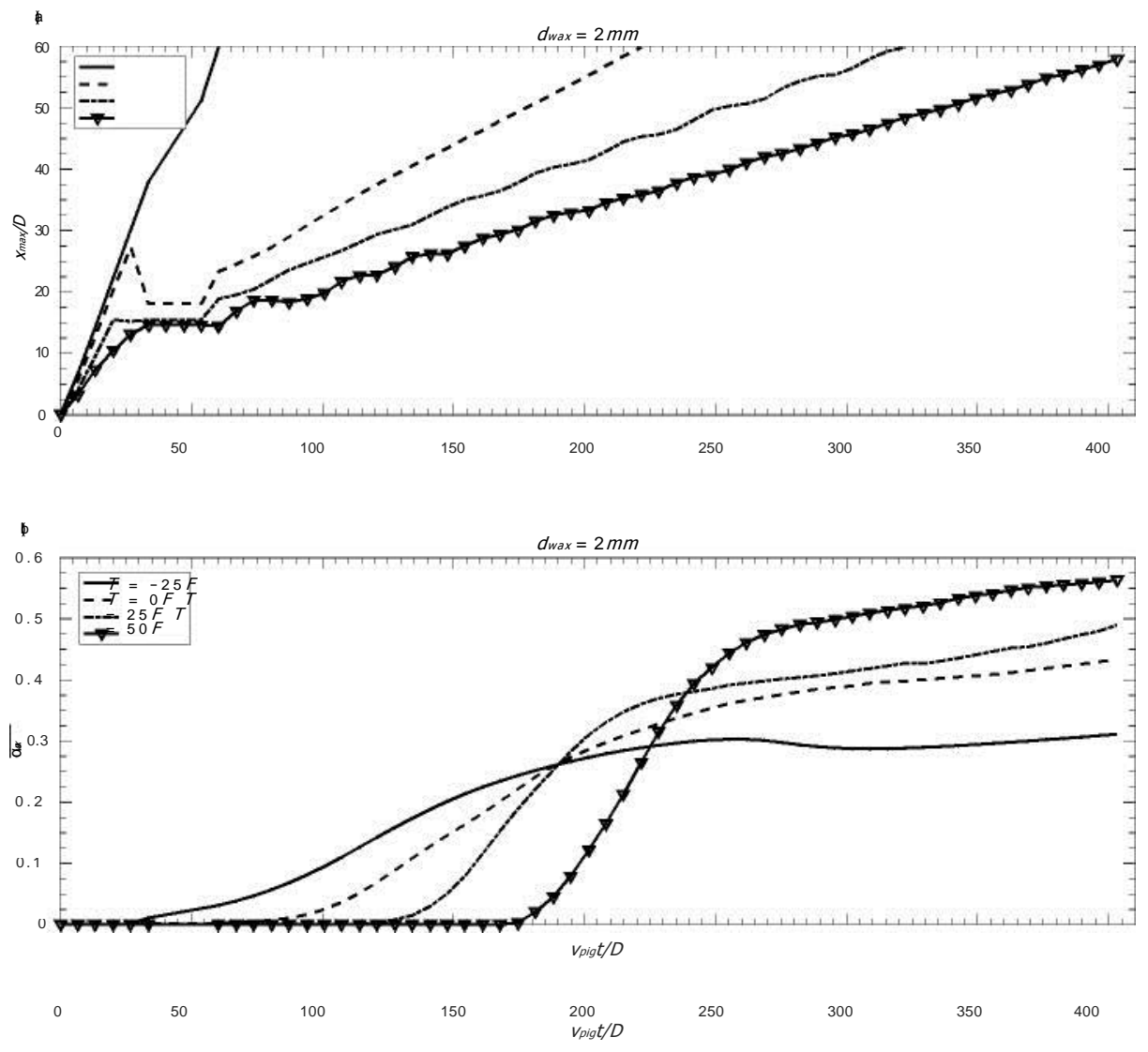

Figure 5: Time growth of wax-in-oil slurry for $d_{\text {wax }}=2 \mathrm{~mm}$. (a) wax-in-oil slurry length vs time; (b) wax volume fraction at $x / D=30$ vs time.

344 the operators. The injection boundary condition, i.e. Eq.(7), for a sealing 345 pig ensures that the wax debris content increases linearly in time for ev346 ery temperature and particle diameter. Therefore, in Fig. $(5, a)$ the growth 347 of the wax-in-oil slurry length in time is shown, while in Fig.(5,b) the in348 crease of wax volume fraction at $x / D=30$ is shown. The time has been ${ }_{349}$ non-dimensionalized using the time scale $D / v p i g$. As far as the wax-in-oil 350 slurry length is concerned, after an initial establishment period, the growth $s_{1}$ is essentially linear in time.

Moreover, the slope of the curve is inversely proportional to the temperature. This is due to the settling, which is higher at higher temperatures. 54 As far as the wax volume fraction at $x / D=30$ is concerned, the variables 

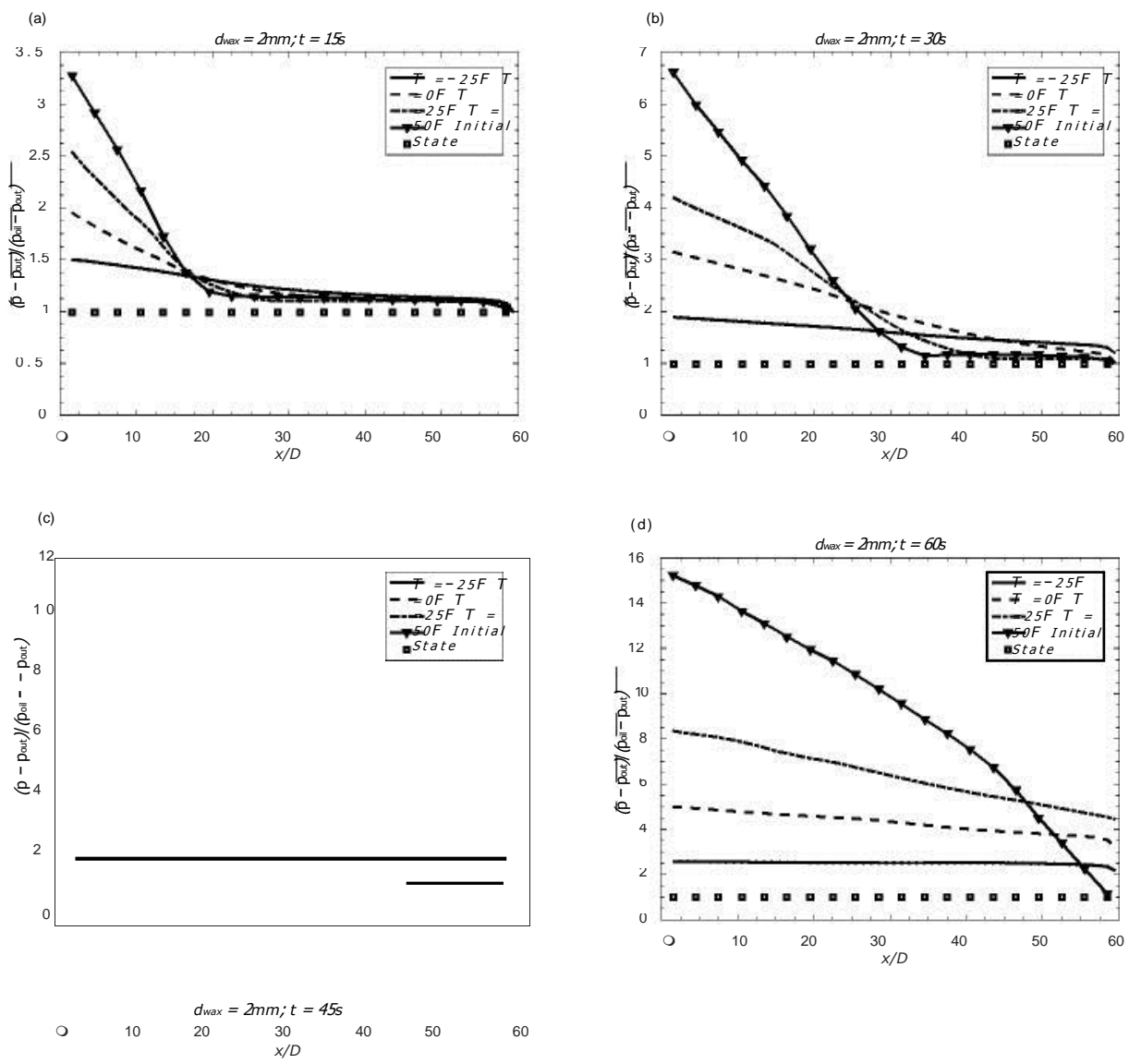

Figure 6: Ratio between the section averaged and the pure oil pressure drop for $\mathrm{d}_{\text {wax }}=2 \mathrm{~mm}$ vs axial distance. (a) $\mathrm{t}=15 \mathrm{~s}$; (b) $\mathrm{t}=30 \mathrm{~s}$; (c) $\mathrm{t}=45 \mathrm{~s}$; (d) $\mathrm{t}=60 \mathrm{~s}$.

355 undergo a phase of fast growth and then stabilize to a certain value. For 356 lower temperatures the growth occurs earlier, but the final volume fraction 357 is smaller. This is also due to the difference in settling.

358 The ratio between the section averaged pressure drop of the mixture, 359 defined in Eq.(27), and the pure oil, defined in Eq.(28), is shown in Fig.(6). 360 The aim of this variable is to show the increase in pressure drop due to 361 the debris field. Despite the absolute pressure drop is lower at the higher 362 temperatures, the pressure drop ratio is higher at higher temperatures.

363 This is due to the fact that the viscosity is inversely proportional to the 364 temperatures. Therefore, the increase of pressure drop is more significant at 365 higher temperatures compared to lower ones. Nevertheless, the increase in 

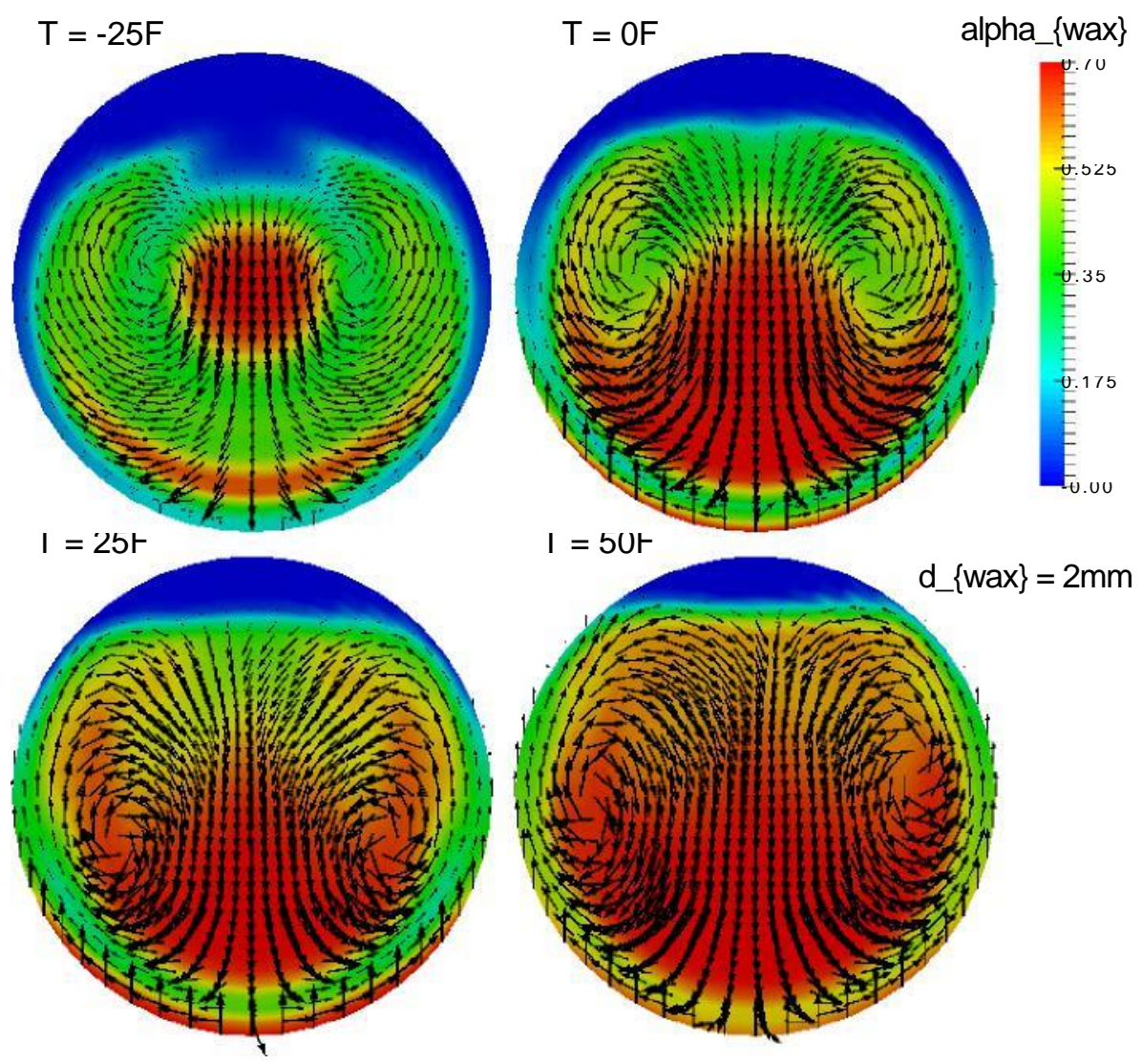

Figure 7: Cut wax planar velocity for $d_{\text {wax }}=2 \mathrm{~mm}, t=60 \mathrm{~s}, x / \mathrm{D}=30$

366 pressure drop due to the debris is not negligible at small temperatures, as it 367 can be seen in Fig.(6) where at $T=-25 F$, the pressure drop ratio is 2.5, 368 while at $T=50 F$ it is 15.5 .

369 In Fig.(7) the planar velocity vectors along with the wax volume fraction 370 field are shown. The velocity vector pattern is highly dependent on the 371 wax debris distribution. At each temperature there is a central region with $372 a_{\text {wax }}=0.7$ surrounded by two counter-rotating vortexes. There is a crescent 373 shaped region with $a_{w a x}=0.7$ towards the bottom. Close to the wall the 374 wax volume fraction is lower, which is responsible for the lubrication effect. 375 The wax chips move towards the bottom and the average volume fraction 376 increases at higher temperatures, as it can be seen in Fig.(4). 

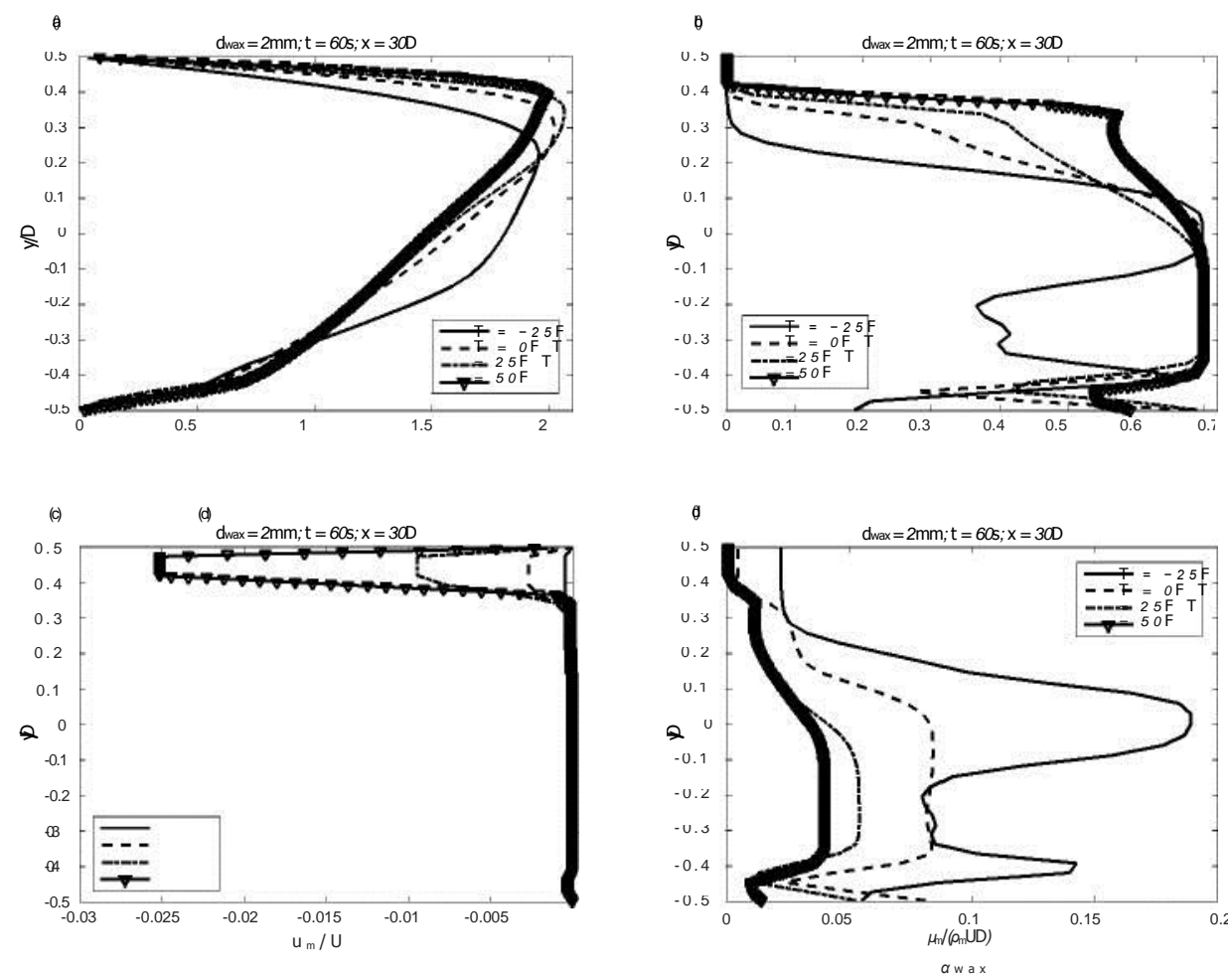

Figure 8: Profiles for $\mathrm{d}_{\text {wax }}=2 \mathrm{~mm}, 60$ seconds after the beginning of the process and 30 diameters downstream the pig. (a) Normalized axial mixture velocity; (b) wax volume fraction; (c) Normalized vertical drift velocity; (d) Normalized Mixture Viscosity. 378 in Eq.(3), is shown. The mixture axial velocity is highly dependent on the 379 local mixture viscosity, shown in Fig. $(8, \mathrm{~d})$ which is scaled by $p_{m} U D$. The 380 velocity gradient decreases with the increasing viscosity in order to ensure the 381 continuity of shear stress at the boundary between the oil and the wax-in-oil 382 slurry. As the temperature increases, the maximum velocity moves towards 383 the pipe top wall because of the higher wax content at the bottom. In ${ }_{384}$ Fig. $(8, c)$ the drift velocity scaled by $U$ is shown. The drift velocity increases 385 in the oil region, in agreement with Eq.(20), and decreases with the increasing 386 temperature, in agreement with Eq.(19). 


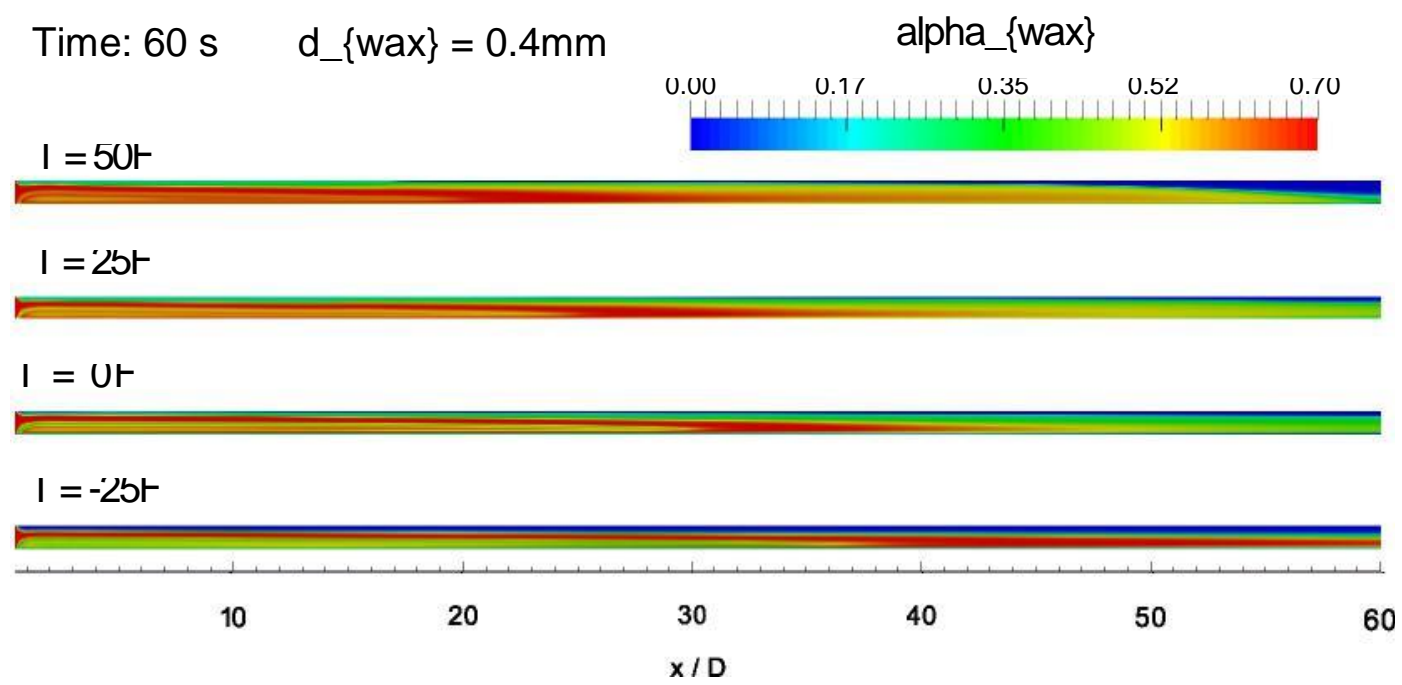

Figure 9: Wax volume fraction field for $0.4 \mathrm{~mm}$ particle diameter at 60 seconds after the beginning of the process.

392 At $T=-25 F$ the results are very similar with those shown in Fig.(3) be393 cause in both cases the drift velocity is small enough to keep the particles in 394 suspension. For the other temperatures, some differences with the previous 395 case can be observed at the end of the domain. The near field is charac396 terized by a layered structure previously observed in Fig.(3). The particle 397 diameter seems to influence the particle deposition mostly in the far-field. 398 This suggests that the morphology of the debris field is mostly determined 399 by the temperature.

400 The reason for this behavior is in the nature of the settling process, which 401 is faster in pure liquids, and slower in slurry. Therefore, the differences 402 between Fig.(3) and Fig.(9) are more evident in the far-field, because the 403 particles fall in the oil and the difference between the settling velocities is 404 not negligible, while in the near-field the particles fall in the wax-in-oil slurry 405 and in both cases the settling velocity is very small. 

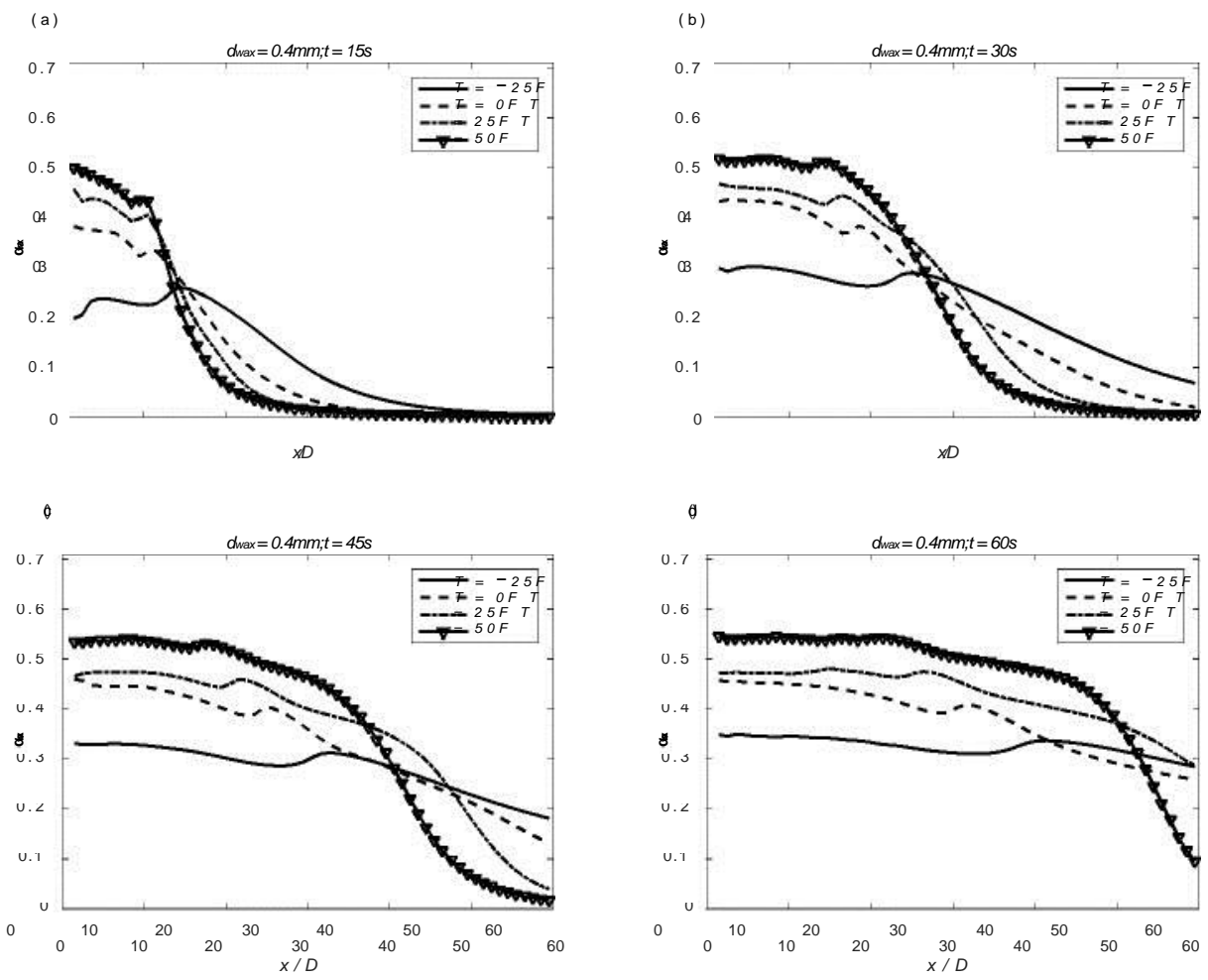

Figure 10: Section averaged cut wax volume fraction field for $2 \mathrm{~mm}$ particle diameter. (a) $\mathrm{t}=$ $15 \mathrm{~s}$; (b) $\mathrm{t}=30 \mathrm{~s} ;$ (c) $\mathrm{t}=45 \mathrm{~s} ;$ (d) $\mathrm{t}=60 \mathrm{~s}$.

413 The profiles in Fig.(10) and Fig.(4) appear to be very similar, with few dif414 ferences. For $\mathrm{d}_{\operatorname{wax}}=0.4 \mathrm{~mm}$, the wax fraction is more uniformly distributed 415 in the pipe compared to $\mathrm{d}_{\text {wax }}=2 \mathrm{~mm}$. For $\mathrm{d}_{\text {wax }}=0.4 \mathrm{~mm}$, the averaged wax 416 fraction is lower in the near field and higher in the far-field as compared to ${ }_{417} \mathrm{~d}_{\text {wax }}=2 \mathrm{~mm}$. This is due to the lower settling velocity which allows the 418 particles to travel further downstream the pipe. 

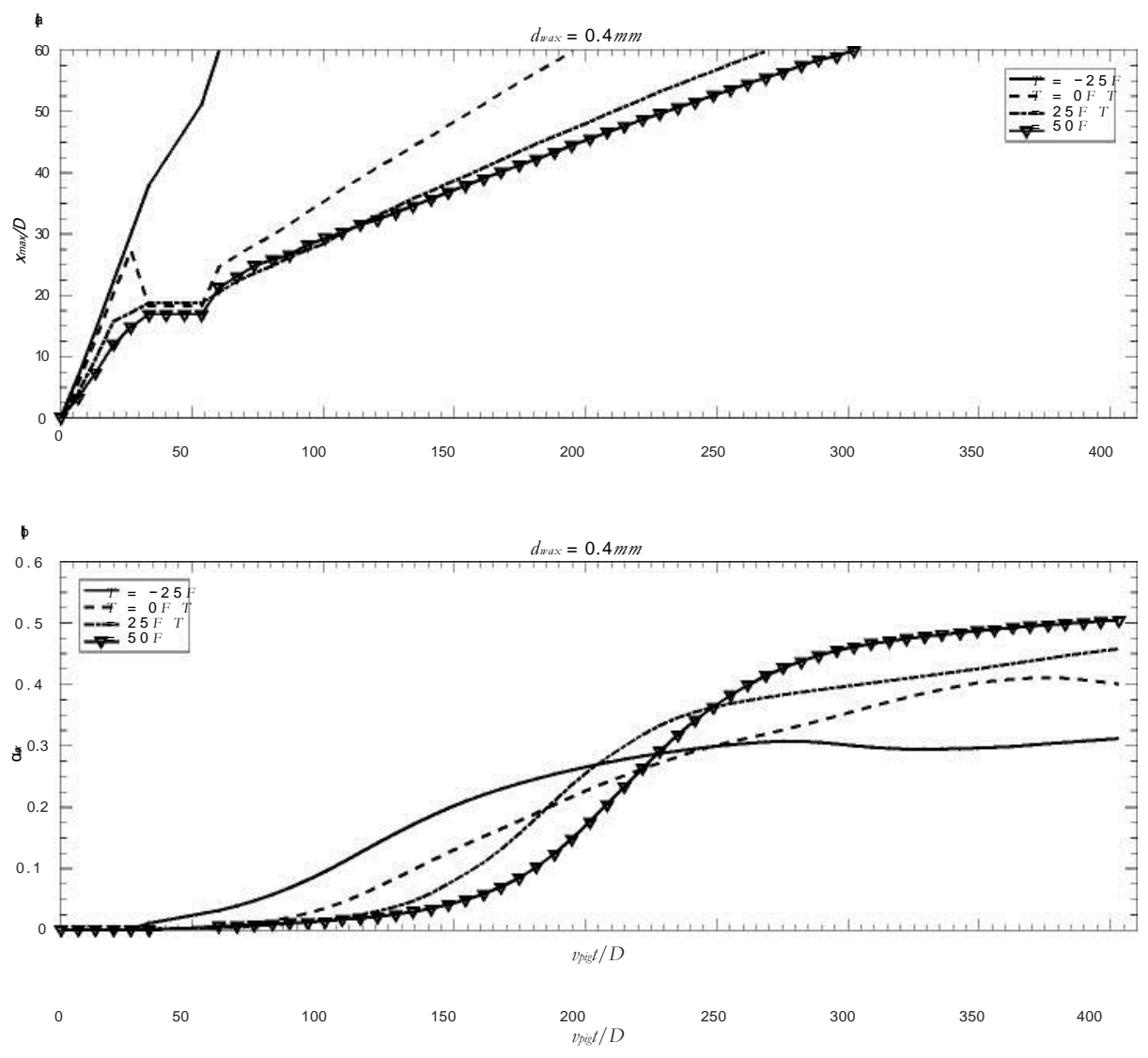

Figure 11: Time growth of wax-in-oil slurry for $\mathrm{d}_{\text {wax }}=0.4 \mathrm{~mm}$. (a) wax-in-oil slurry length vs time; (b) wax volume fraction at $\mathrm{x} / \mathrm{D}=30$ vs time.

In Fig. $(11, a)$ the growth of the wax-in-oil slurry length in time is shown, 20 while in Fig. $(11, b)$ the increase of wax volume fraction at $x / D=30$ is shown. ${ }_{421}$ The time has been non-dimensionalized using the time scale $D / v p i g$. As for ${ }_{422}$ the previous case, the growth is essentially linear in time with the slope of ${ }_{423}$ the curve inversely proportional to the temperature. Comparing Fig. $(11, \mathrm{a})$ ${ }_{424}$ with Fig. $(5, \mathrm{a})$ it can be seen that the growth is quicker for $d_{\text {wax }}=0.4 \mathrm{~mm}$ ${ }_{425}$ due to the lower settling.

426 As far as the wax volume fraction at $x / D=30$ is concerned, comparing ${ }_{427}$ Fig. $(11, b)$ with Fig. $(5, b)$ it can be seen that for every temperature the growth ${ }_{428}$ occurs earlier, but the final volume fraction is smaller, which is also due to 429 the reduced settling. 

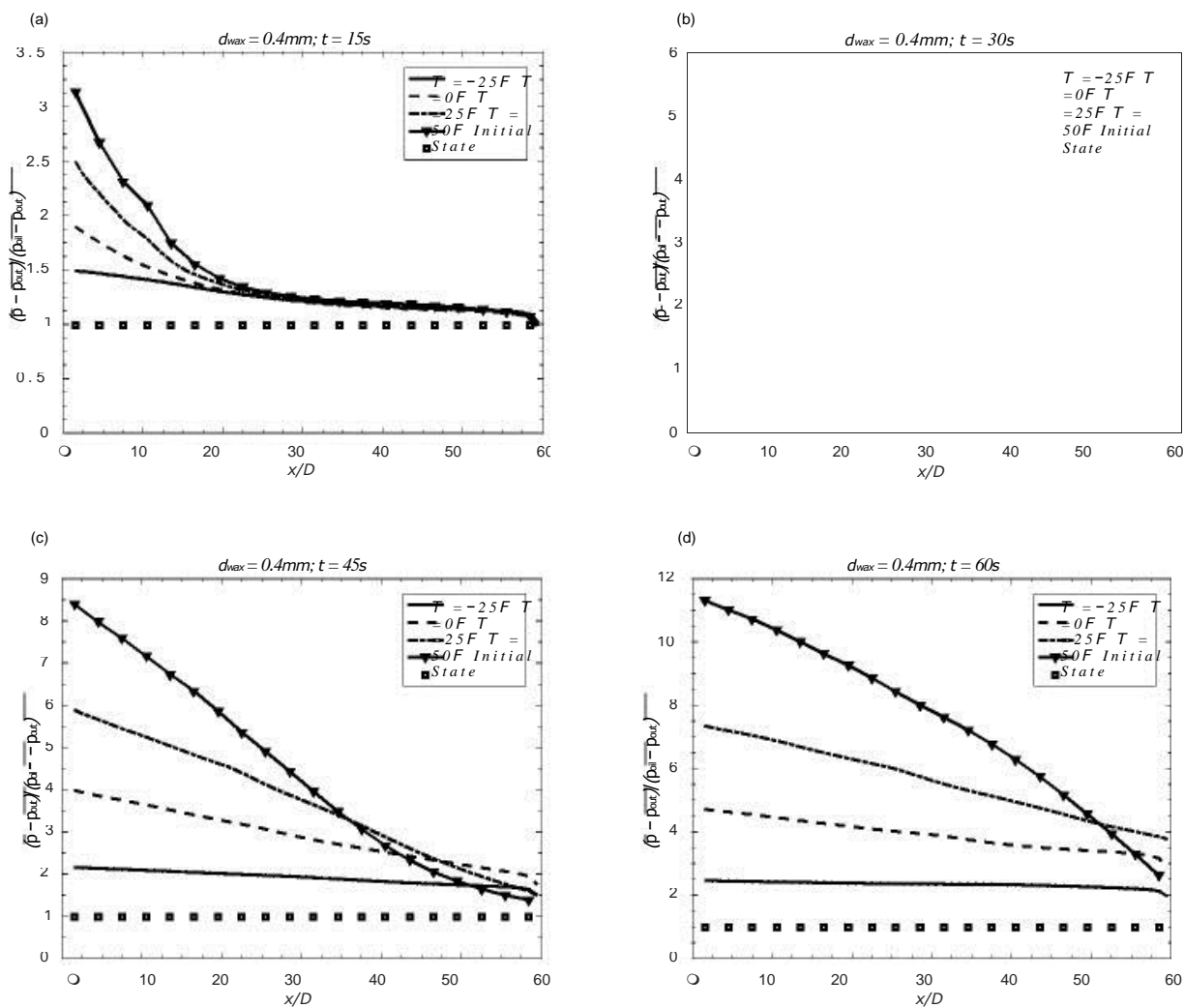

Figure 12: Ratio between the section averaged and the pure oil pressure drop for $\mathrm{d}_{\text {wax }}=0.4 \mathrm{~mm}$ vs axial distance. (a) $\mathrm{t}=15 \mathrm{~s}$; (b) $\mathrm{t}=30 \mathrm{~s}$; (c) $\mathrm{t}=45 \mathrm{~s}$; (d) $\mathrm{t}=60 \mathrm{~s}$.

In Fig.(12), the ratio between the section averaged pressure drop of the 431 mixture and the pure oil, is shown. This variable is obtained from the ratio 432 between the expressions in Eq.(27) and Eq.(28). Comparing the profiles in ${ }_{433}$ Fig.(12) and Fig.(6), it can be seen that, in analogy with the previous case, 434 the pressure drop increases in the presence of debris. Nevertheless, this effect 435 is less pronounced as compared to Fig.(6). We can conclude that the pressure ${ }_{436}$ drop decreases for decreasing particle diameters. From this result, we can 437 hypothesize that any mechanism promoting particle breakage, as a jet for 438 instance, may reduce the pressure drop.

$439 \quad$ In Fig.(13) the planar velocity vectors along with the wax volume fraction 440 field are shown. In general, the motion is more dispersed as compared to the 

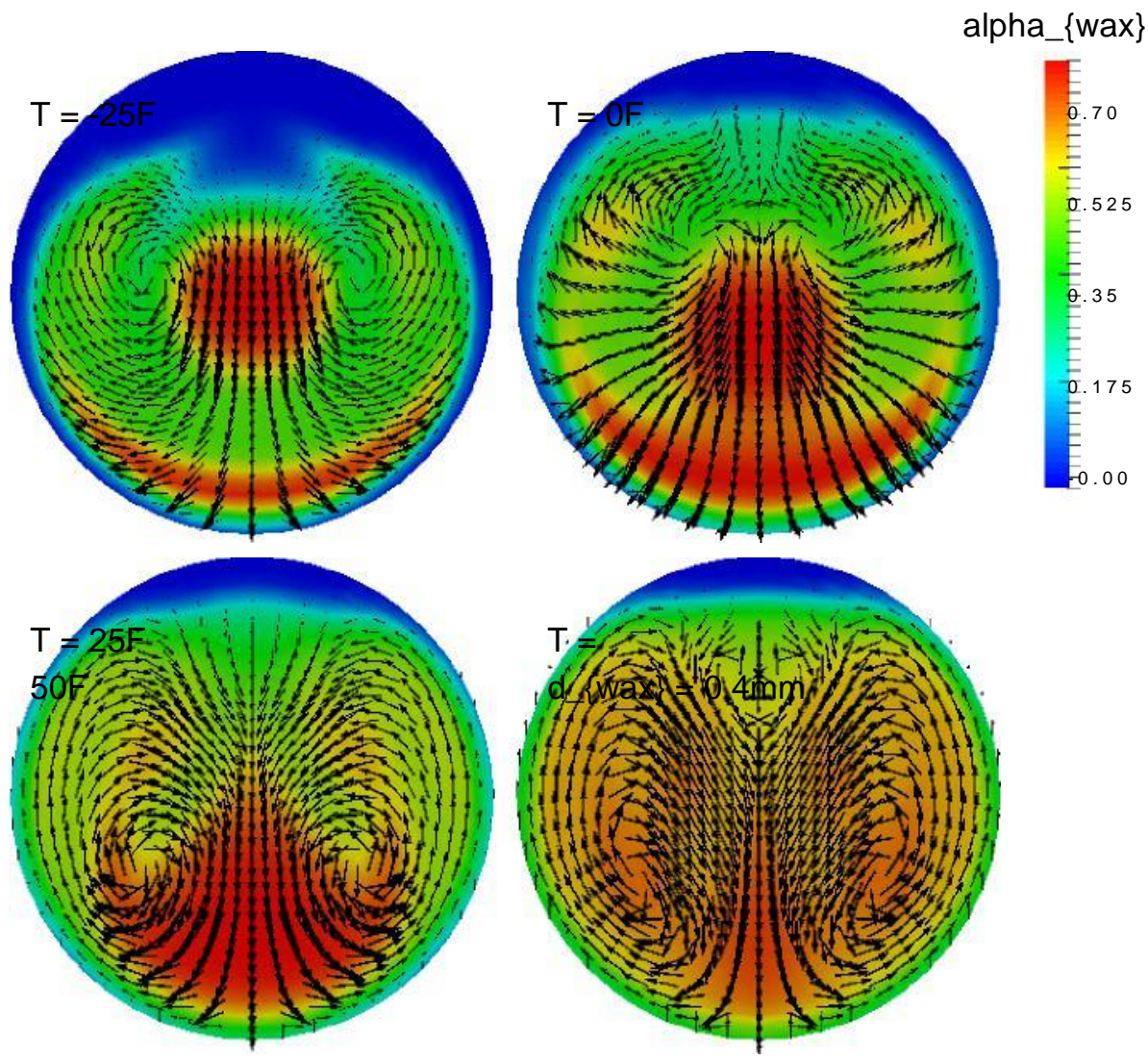

Figure 13: Cut wax planar velocity for $d_{\operatorname{wax}}=0.4 \mathrm{~mm}, t=60 \mathrm{~s}, x / D=30$.

441 previous case. For $T=-25 F$, the particle diameter has scarce influence on 442 the solution. For the other temperatures some differences with the previous 443 case can be observed: the wax content is lower, as it can be deduced by 444 comparing Fig.(10) with Fig.(4), and the counter-rotating vortexes are closer 445 to the top of the pipe. At $T=50 \mathrm{~F}$, the velocity fields for the $d_{\text {wax }}=2 \mathrm{~mm}$ 446 and $d_{\text {wax }}=0.4 \mathrm{~mm}$ appear very different. For $d_{\text {wax }}=0.4 \mathrm{~mm}$ the vortexes are 447 in the lower part of the pipe and their major axes are inclined with respect 448 to the vertical axis of $\pm i r / 4$. For $d_{w a x}=2 \mathrm{~mm}$, the vortexes are located at 449 the center of the section and their major axes are parallel to the vertical axis. $450 \quad$ In Fig.(14,a), the mixture axial velocity, scaled by the velocity $U$, defined 451 in Eq.(3), is shown. Comparing this result with Fig. $(8, a)$ it can be seen that 

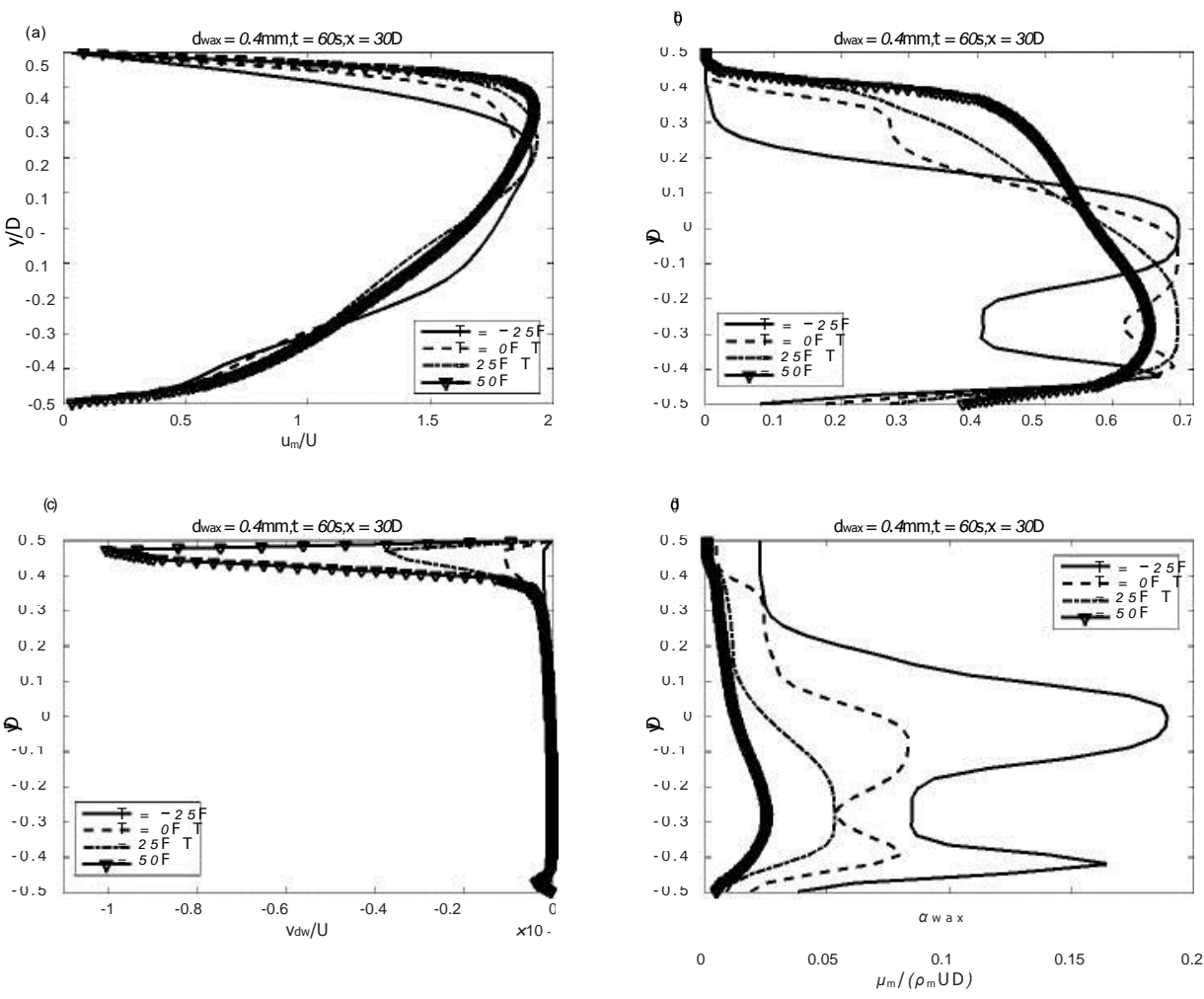

Figure 14: Profiles for $\mathrm{d}_{\text {wax }}=0.4 \mathrm{~mm}, 60$ seconds after the beginning of the process and 30 diameters downstream the pig. (a) Normalized axial mixture velocity; (b) wax volume fraction; (c) Normalized vertical drift velocity; (d) Normalized Mixture Viscosity.

452 the profiles are smoother and the maximum velocity is lower. This is due to 453 the fact that the wax distribution is more uniform and therefore the viscosity 454 profile is smoother, as it can be seen comparing Fig.(8,d) with Fig.(14,d). 455 The variable which is mostly influenced by the particle diameter is the drift 456 velocity since is proportional to the settling velocity. Comparing Fig. $(8, c)$ 457 with Fig. $(14, c)$ it can be seen that the two profiles have a similar shape, 458 with the maximum in the oil region and decaying to zero for awax

459 Furthermore, in agreement with Eq.(19), the drift velocity maximum is 25 460 times smaller for $\mathrm{d}_{\text {wax }}=0.4 \mathrm{~mm}$ as compared to $\mathrm{d}_{\text {wax }}=2 \mathrm{~mm}$. 


\section{5. Discussion}

462 The results of the present 3D numerical investigation reveal some im463 portant details about the debris flow, which could not be derived from 1D 464 analysis. Comparing Fig.(3) with Fig.(4), and Fig.(9) with Fig.(10), it can 465 be seen that the $1 \mathrm{D}$ information is more representative of the $3 \mathrm{D}$ debris field 466 at high temperatures, e.g. $\mathrm{T}=50 \mathrm{~F}$. At lower temperatures, the information 467 concerning the stratification are lost.

468 The results of Fig.(3) and Fig.(9) show that the temperature has a greater 469 influence on the debris field than the particle diameter. In agreement with ${ }_{470}$ Eq.(19), the debris field is more dispersed for lower temperatures and particle ${ }_{471}$ diameters. In this work the mixture flows in laminar regime, however, in 472 larger pipelines turbulence is an important factor (Patrachari \& Johannes 473 (2012)). At higher Reynolds numbers, the competition between turbulence 474 and settling could keep the particle in suspension and it is unclear if small 475 enough debris remain suspended. Answering this question is beyond the 476 purpose of this work, however, the results in Figs. $(7,13)$, show that, in the 477 pipe cross-section there is a whirling motion which favors particle deposition. ${ }_{478}$ Moreover, the unsteady 3D results show a very similar debris distribution for 479 the different particle diameters.

480 Despite the fact that turbulence may occur for higher oil flow rates, the ${ }_{481}$ high wax-in-oil slurry viscosity is likely to restore the laminar flow over time. 482 In presence of a stratified flow, pure oil flows in a narrow section at the 483 top of the pipe. From the results in Fig. $(8, a)$ and Fig. $(14, a)$ it is clear that 484 the oil flow is laminar. The oil speed can play an important role in the 485 determination of the height of the wax-in-oil slurry, which has a "dune" 486 shape. Comparing Fig.(4) and Fig.(10), it can be seen that the height of the ${ }_{487}$ dune is proportional to the temperatures. Since for higher temperatures the 488 oil viscosity decreases, Fig. $(2, b)$, while the oil velocity at the top of the pipe 489 increases, Fig. $(8, a)$ and Fig. $(14, a)$, it seems that the height of the dune is 490 adjusted in order to have roughly the same friction for every temperature. ${ }_{491}$ This hypothesis needs further investigation.

492 Another important information lost in the 1D analysis is the vertical ${ }_{493}$ distribution of the different variables. What can be seen from Fig. (8,a) and ${ }_{494}$ Fig. $(14, a)$ is that the axial velocity profile is not flat but has a rather parabolic 495 shape, because of the low Reynolds number. If the debris field is stratified, 496 the maximum velocity is found at the top of the pipe, where the lighter fluid 497 is. If the debris field is dispersed, the velocity profile is more symmetric. 
${ }_{498}$ This is due to the fact that the shape of the velocity profile is determined by 499 the mixture viscosity, which depends on the wax volume fraction.

500 The non-uniform axial velocity field is the reason for the increase in time 501 of the wax-in-oil slurry. If the velocity profile was flat, the wax chips could 502 travel only as fast as the pig and accumulate in front of its body. However, 503 because every viscous fluid respects the no-slip condition at the wall, the 504 velocity at the center of the pipe must be higher than the mean velocity. In 505 the case of a single-phase laminar motion, the maximum velocity is twice the 506 mean one. The wax chips at the center of the pipe travel farther than the 507 pig until they settle at a certain distance. Since the velocity at the boundary 508 layer approaches zero, the fallen chips are slower than the pig, and after 509 a certain period they will be re-scraped and re-injected into the pipe. The 510 viscosity of the wax-in-oil slurry, shown in Fig.(8,a) and Fig.(14,a), influences 511 the particle deposition. A high viscosity increases the friction, slowing down 512 the chips, but reduces the settling, delaying the deposition.

${ }_{513} \quad$ As far as the pressure drop is concerned, the results in Fig.(6) and ${ }_{514}$ Fig.(12), show that it is mostly influenced by the temperature rather than 515 the particle diameter. The purpose of Fig.(6) and Fig.(12) is to quantify 516 the pressure drop increase due to the debris field. Despite the pressure drop 517 being higher at lower temperatures, the debris field has a greater influence ${ }_{518}$ for higher temperatures. The pressure drop increases with time because of ${ }_{519}$ the increased suspended debris. This behavior must be carefully monitored 520 to estimate the risk of a wax plug. As time goes by, the pump may not be 521 able to deliver enough pressure, and the pig may slow down and stop. In the 522 present model this scenario cannot take place because of the fixed flow rate 523 boundary condition. This constraint allows the pressure to increase at will 524 in order to satisfy the boundary condition.

$525 \quad$ Our results show that the temperature has a fundamental importance 526 in determining the flow of the wax-in-oil slurry. In this work, the motion 527 has been considered isothermal because a short and non-heated pipeline has 528 been investigated. It would be necessary to introduce the energy equation to 529 study heated or longer pipelines in the future.

$530 \quad$ Improved pig and slurry viscosity models are under investigation. Further 531 experimental data are required to include the influence of non-Newtonian 532 rheology and pour point. Nevertheless, the present formulation of debris ${ }_{533}$ dependent viscosity is sufficient to show the qualitative mechanisms involved 534 in debris transport and deposition. The effect of a bypass at the center of 535 the pig is also under investigation. 


\section{${ }_{536}$ 6. Conclusions}

537 A 3D numerical investigation of the fluid dynamics of the wax-in-oil slurry, 538 subject to pigging operations, has been conducted in this work. The drift 539 flux model has been used to simulate the flow of the slurry. The pig was 540 modeled as a cylindrical body moving at constant speed in the pipe, due to 541 the constant oil flow rate at the inlet. An injection boundary condition for 542 the wax chips, equivalent to the scraping, but numerically more efficient, has 543 been introduced. The properties of the two fluids have been experimentally ${ }_{544}$ derived. The influence of temperature and particle dimensions on the flow 545 has been investigated.

546 The 3D simulations provide details, such as the axial velocity profiles, 547 planar velocity vectors, and wax volume fraction field, which improve our 548 comprehension of the dynamics of the process. This information can be used 549 to improve the existing 1D models. Our group is currently investigating 550 improvements of the present model as well as the influence of a bypass at the 551 center of the pig.

\section{7. Acknowledgments}

553 The authors would like to thank the anonymous reviewers for their very 554 helpful effort, their comments and suggestions improved the quality of the 555 paper. The authors also thank Mr Rishabh Ishar for helpful suggestions in 556 editing the manuscript. This research did not receive any specific grant from 557 funding agencies in the public, commercial, or not-for-profit sectors.

\section{${ }_{558}$ References}

Aarsnes, U. J. F., Ambrus, A., Di Meglio, F., Vajargah, A. K., Aamo, 560 O. M., \& van Oort, E. (2016). A simplified two-phase flow model using a 561 quasi-equilibrium momentum balance. International Journal of Multiphase 562 Flow, 83, 77-85.

63 Aiyejina, A., Chakrabarti, D. P., Pilgrim, A., \& Sastry, M. (2011). Wax 564 formation in oil pipelines: A critical review. International Journal of Mul565 tiphase Flow, 37, 671-694.

566 Al-Nassri, S. A., \& Unny, T. (1981). Developing laminar flow in the inlet length of a smooth pipe. Applied Scientific Research, 36, 313-332. 
68 Asheim, H., \& Grødal, E. (1998). Holdup propagation predicted by steady569 state drift flux models. International Journal of Multiphase Flow, 24, $570 \quad 757-774$.

Azevedo, L., Bracm, A., Nieckele, A., Naccxhe, M., Gomes, M. et al. (1996). 572 Simple hydrodynamicmodels for the prediction of pig motions in pipelines. 573 In Offshore Technology Conference (pp. 729-739). Offshore Technology 574 Conference.

575 Azevedo, L., Braga, A., Nieckele, A., \& Souza Mendes, P. (1999). simulating 576 pipeline pigging operations. In Proc. The Pipeline Pigging Conference, 577 Stavanger, Norway (pp. 1-21).

78 Barros Jr, J., Alves, D., Barroso, A., Souza, R., \& Azevedo, L. (2005). Exper579 imental validation of models for predicting wax removal forces in pigging 580 operations. In Proceedings of 18th International Congress of Mechanical 581 Engineering, Ouro Preto, MG, Brazil (pp. 6-11).

582 Barua, S. (1982). An Experimental Verification and Modification of the 583 McDonald-Baker Pigging Model for Horizontal Flow. Ph.D. thesis Uni584 versity of Tulsa, OK.

585 Bhagwat, S. M., \& Ghajar, A. J. (2014). A flow pattern independent drift 586 flux model based void fraction correlation for a wide range of gas-liquid 587 two phase flow. International Journal of Multiphase Flow, 59, 186-205.

588 Braga, A., Azevedo, L., \& Correa, K. (1999). Resistive force of wax deposits 589 during pigging operations. Journal of Energy Resources Technology, 121, $590 \quad 167-171$.

591 Camenen, B. (2008). Settling velocity of sediments at high concentrations. 592 Proceedings in Marine Science, 9, 211-226.

${ }_{593}$ Chen, S.-W., Liu, Y., Hibiki, T., Ishii, M., Yoshida, Y., Kinoshita, I., Murase, $594 \quad$ M., \& Mishima, K. (2012). One-dimensional drift-flux model for two-phase 595 flow in pool rod bundle systems. International Journal of Multiphase Flow, $59640,166-177$.

597 Clark, N., Van Egmond, J., \& Nebiolo, E. (1990). The drift-flux model 598 applied to bubble columns and low velocity flows. International Journal 599 of Multiphase Flow, 16, 261-279. 
500 Deng, T., Gong, J., Zhou, J., Zhang, Y., \& Li, H. (2014). Numerical sim ulation of the effects of vaporization on the motion of pig during pigging process. Asia-Pacific Journal of Chemical Engineering, 9, 854-865.

Esmaeilzadeh, F., Mowla, D., \& Asemani, M. (2009). Mathematical modeling and simulation of pigging operation in gas and liquid pipelines. Journal of Petroleum Science and Engineering, 69, 100-106.

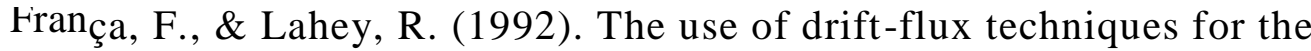
analysis of horizontal two-phase flows. International Journal of Multiphase Flow, 18, 787-801.

Galta, T. (2014). Bypass Pigging of Subsea Pipelines Suffering Wax Deposition. Master's thesis Institutt for petroleumsteknologi og anvendt geofysikk.

Gavrilyuk, S., \& Fabre, J. (1996). Lagrangian coordinates for a drift-flux model of a gas-liquid mixture. International Journal of Multiphase Flow, $22,453-460$.

Hosseinalipour, S., Khalili, A. Z., \& Salimi, A. (2007a). Numerical simulation of pig motion through gas pipelines. In 16th Australian Fluid Mechanics Conference, Goald Coast Australia. volume 12.

Hosseinalipour, S., Salimi, A., \& Khalili, A. Z. (2007b). Transient flow and pigging operation in gas-liquid two phase pipelines. In 16th Australasian Fluid Mechanics Conference Crown Plaza, Gold Coast, Australia (pp. 976979).

Hovden, L., Labes-Carrier, C., Rydahl, A., Ronningsen, H., \& Xu, Z. (2003). Pipeline wax deposition models and model for removal of wax by pigging: Comparison between model predictions and operational experience. In Abstracts of Papers of the American Chemical Society (pp. U936-U936). Amer Chemical Soc 1155 16TH ST, NW, Washington, DC 20036 USA volume' 2 's.

Hu, Z., \& Appleton, E. (2005). Dynamic characteristics of a novel self-drive pipeline pig. Robotics, IEEE Transactions on, 21, 781-789. 
630 Huang, Q., Wang, W., Li, W., Ren, Y., Zhu, F. et al. (2016). A pigging 631 model for wax removal in pipes. In SPE Annual Technical Conference and 632 Exhibition (pp. 1-11). Society of Petroleum Engineers.

63 Kim, D. K., Cho, S. H., Park, S. S., Rho, Y. W., Yoo, H. R., Nguyen, T. T., $634 \&$ Kim, S. B. (2003). Verification of the theoretical model for analyzing 635 dynamic behavior of the pig from actual pigging. KSME International 636 Journal, 17, 1349-1357.

637 Kohda, K., Suzukawa, Y., \& Furukawa, H. (1988). New method for analyzing 638 transient flow after pigging scores well. Oil and Gas Journal, 86, 40-47.

639 Lesani, M., Rafeeyan, M., \& Sohankar, A. (2012). Dynamic analysis of small 640 pig through two and three-dimensional liquid pipeline. Journal of Applied 641 Fluid Mechanics, 5, 75-83.

642 Lima, P., Alves, S. et al. (1995). Application of low density foam pigs offshore 643 brazil. In Annual Offshore Technology Conference (pp. 529-529). Offshore 644 Technology Conference volume 3.

645 Lima, P., Yeung, H. et al. (1998). Modeling of transient two-phase flow 646 operations and offshore pigging. In SPE Annual Technical Conference and 647 Exhibition. Society of Petroleum Engineers.

648 Lima, P., Yeung, H. et al. (1999). Modeling of pigging operations. In SPE 649 Annual Technical Conference and Exhibition. Society of Petroleum Engi650 neers.

51 Low Flow Study Project Team (2011). Low Flow Impact Study FINAL RE652 PORT. Technical Report Alyeska Pipeline.

653 McDonald, A. E., \& Baker, O. (1964). A method of calculating multiphase 654 flow in pipe lines using rubber spheres to control liquid holdup. Drilling 655 and Production Practice, (pp. 56-68).

656 Minami, K., \& Shoham, O. (1995). Pigging dynamics in two-phase flow 657 pipelines: Experiment and modeling. Society of Petroleum Engineers, 10, $658 \quad 225-232$.

659 Mirshamsi, M., \& Rafeeyan, M. (2015). Dynamic analysis of pig through two 660 and three dimensional gas pipeline. Journal of Applied Fluid Mechanics, $6618,43-54$. 
662 Nguyen, T. T., Kim, D. K., Rho, Y. W., \& Kim, S. B. (2001a). Dynamic 663 modeling and its analysis for pig flow through curved section in natural 664 gas pipeline. In Computational Intelligence in Robotics and Automation, 665 2001. Proceedings 2001 IEEE International Symposium on (pp. 492-497).

666 IEEE.

667 Nguyen, T. T., Kim, S. B., Yoo, H. R., \& Rho, Y. W. (2001b). Modeling and 668 simulation for pig flow control in natural gas pipeline. KSME International 669 Journal, 15, 1165-1173.

670 Nguyen, T. T., Kim, S. B., Yoo, H. R., \& Rho, Y. W. (2001c). Modeling and 671 simulation for pig with bypass flow control in natural gas pipeline. KSME 672 International Journal, 15, 1302-1310.

673 Nguyen, T. T., Yoo, H. R., Rho, Y. W., \& Kim, S. B. (2001d). Speed control 674 of pig using bypass flow in natural gas pipeline. In Industrial Electronics, 675 2001. Proceedings. ISIE 2001. IEEE International Symposium on (pp. 863676 868). IEEE volume 2.

677 Nieckele, A., Braga, A., \& Azevedo, L. (2001). Transient pig motion through 678 gas and liquid pipelines. Journal of Energy Resources Technology, 123, $679 \quad 260-269$.

680 Patrachari, A. R., \& Johannes, A. H. (2012). A conceptual framework to 681 model interfacial contamination in multiproduct petroleum pipelines. In682 ternational Journal of Heat and Mass Transfer, 55, 4613-4620.

683 Rusche, H. (2003). Computational Fluid Dynamics of Dispersed Two-Phase 684 Flows at High Phase Fractions. Ph.D. thesis Imperial College London 685 (University of London).

686 Saeidbakhsh, M., Rafeeyan, M., \& Ziaei-Rad, S. (2009). Dynamic analysis 687 of small pigs in space pipelines. Oil \& Gas Science and Technology-Revue 688 de l'IFP, 64, 155-164.

689 Southgate, J. (2004). Wax Removal Using Pipeline Pigs. Ph.D. thesis 690 Durham University.

691 Tan, G.-B., Liu, S.-H., Wang, D.-G., \& Zhang, S.-W. (2015a). Spatio692 temporal structure in wax-oil gel scraping at a soft tribological contact.

693 Tribology International, 88, 236-251. 
${ }_{69}$ Tan, G.-B., Liu, S.-H., Wang, D.-G., \& Zhang, S.-W. (2015b). Tribologi695 cal behaviours of wax-in-oil gel deposition in orthogonal cleaning process.

696 Tribology Letters, 57, 1-18.

97 Tan, G.-B., Wang, D.-G., Liu, S.-H., \& Zhang, S.-W. (2014). Probing tri698 bological properties of waxy oil in pipeline pigging with fluorescence tech699 nique. Tribology International, 71, 26-37.

${ }_{00}$ Tolmasquim, S. T., \& Nieckele, A. O. (2008). Design and control of pig oper701 ations through pipelines. Journal of Petroleum Science and Engineering, $702 \quad 62,102-110$.

703 Varadarajan, P. A., \& Hammond, P. S. (2015). Numerical scheme for accu704 rately capturing gas migration described by 1d multiphase drift flux model. 705 International Journal of Multiphase Flow, 73, 57-70.

${ }_{06}$ Vorobev, A., \& Boghi, A. (2016). Phase-field modelling of a miscible system 707 in spinning droplet tensiometer. Journal of Colloid and Interface Science, 708 482, 193-204.

${ }_{09}$ Wang, Q., Sarica, C., \& Chen, T. X. (2005). An experimental study on 710 mechanics of wax removal in pipeline. Journal of Energy Resources Tech711 nology, 127, 302-309.

712 Wang, Q., Sarica, C., \& Volk, M. (2008). An experimental study on wax 713 removal in pipes with oil flow. Journal of Energy Resources Technology, $714 \quad 130,043001$.

${ }_{15}$ Wang, W., \& Huang, Q. (2014). Prediction for wax deposition in oil pipelines 716 validated by field pigging. Journal of the Energy Institute, 87, 196-207.

17 Wang, W., Huang, Q., Liu, Y., Sepehrnoori, K. et al. (2015). Experimental 718 study on mechanisms of wax removal during pipeline pigging. In SPE An719 nual Technical Conference and Exhibition (pp. 1-25). Society of Petroleum 720 Engineers.

1 Xu, X.-X., \& Gong, J. (2005). Pigging simulation for horizontal gas condensate pipelines with low-liquid loading. Journal of Petroleum Science and Engineering, 48, 272-280. 